\title{
Schistosomiasis Morbidity Hotspots: Roles of the Human Host, the Parasite and Their Interface in the Development of Severe Morbidity
}

\section{OPEN ACCESS}

Edited by:

Thiago Almeida Pereira, Stanford University, United States

Reviewed by: Justin Komguep Nono, Ministry of Scientific Research and Innovation, Cameroon William Evan Secor, Centers for Disease Control and Prevention (CDC), United States

*Correspondence: Patrice A. Mawa patrice.mawa@/shtm.ac.uk

${ }^{\dagger}$ These authors have contributed equally to this work

Specialty section:

This article was submitted to Microbial Immunology, a section of the journal

Frontiers in Immunology

Received: 30 November 2020 Accepted: 25 February 2021 Published: 12 March 2021

Citation:

Mawa PA, Kincaid-Smith J, Tukahebwa EM, Webster JP and Wilson S (2021) Schistosomiasis Morbidity Hotspots: Roles of the Human Host, the Parasite and Their Interface in the Development of Severe Morbidity.

Front. Immunol. 12:635869. doi: 10.3389/fimmu.2021.635869

\begin{abstract}
Patrice A. Mawa ${ }^{1,2,3^{*}+}$, Julien Kincaid-Smith ${ }^{4 \dagger}$, Edridah M. Tukahebwa ${ }^{5}$, Joanne P. Webster ${ }^{4}$ and Shona Wilson ${ }^{6}$

1 Immunomodulation and Vaccines Programme, Medical Research Council-Uganda Virus Research Institute and London School of Hygiene and Tropical Medicine (MRC/UVRI and LSHTM) Uganda Research Unit, Entebbe, Uganda, ${ }^{2}$ Department of Immunology, Uganda Virus Research Institute, Entebbe, Uganda, ${ }^{3}$ Department of Infection Biology, London School of Hygiene and Tropical Medicine, London, United Kingdom, ${ }^{4}$ Centre for Emerging, Endemic and Exotic Diseases (CEEED), Department of Pathobiology and Population Sciences (PPS), Royal Veterinary College, University of London, Herts, United Kingdom, ${ }^{5}$ Vector Control Division, Ministry of Health, Kampala, Uganda, ${ }^{6}$ Department of Pathology, University of Cambridge, Cambridge, United Kingdom
\end{abstract}

Schistosomiasis is the second most important human parasitic disease in terms of socioeconomic impact, causing great morbidity and mortality, predominantly across the African continent. For intestinal schistosomiasis, severe morbidity manifests as periportal fibrosis (PPF) in which large tracts of macro-fibrosis of the liver, visible by ultrasound, can occlude the main portal vein leading to portal hypertension (PHT), sequelae such as ascites and collateral vasculature, and ultimately fatalities. For urogenital schistosomiasis, severe morbidity manifests as pathology throughout the urinary system and genitals, and is a definitive cause of squamous cell bladder carcinoma. Preventative chemotherapy (PC) programmes, delivered through mass drug administration (MDA) of praziquantel (PZQ), have been at the forefront of schistosomiasis control programmes in subSaharan Africa since their commencement in Uganda in 2003. However, despite many successes, 'biological hotspots' (as distinct from 'operational hotspots') of both persistent high transmission and morbidity remain. In some areas, this failure to gain control of schistosomiasis has devastating consequences, with not only persistently high infection intensities, but both "subtle" and severe morbidity remaining prevalent. These hotspots highlight the requirement to revisit research into severe morbidity and its mechanisms, a topic that has been out of favor during times of PC implementation. Indeed, the focality and spatially-structured epidemiology of schistosomiasis, its transmission persistence and the morbidity induced, has long suggested that gene-environmental-interactions 
playing out at the host-parasite interface are crucial. Here we review evidence of potential unique parasite factors, host factors, and their gene-environmental interactions in terms of explaining differential morbidity profiles in the human host. We then take the situation of schistosomiasis mansoni within the Albertine region of Uganda as a case study in terms of elucidating the factors behind the severe morbidity observed and the avenues and directions for future research currently underway within a new research and clinical trial programme (FibroScHot).

Keywords: schistosomiasis, biological hotspot, morbidity, host-parasite-environmental-factors, FibroScHot

\section{INTRODUCTION}

Species of the genus Schistosoma are digenetic trematodes and the causative agents of the Neglected Tropical Disease (NTD) schistosomiasis; a parasitic disease that ranks second only to malaria in terms of socioeconomic impacts. Over 220 million people worldwide are currently infected, $90 \%$ of whom live in sub-Saharan Africa (SSA) $(1,2)$, with an estimated annual mortality of at least 200,000 (3). Infection in humans, as well as alternative mammalian definitive hosts, occurs in contaminated freshwater environments via cercariae shed from specific snail intermediate hosts. Early acute morbidity can occur following cutaneous penetration, sometimes leading to an urticarial rash known as swimmers itch or cercarial dermatitis $(4,5)$. After entering the host, schistosomes migrate through the body to mature to adulthood in the liver. This phase can also involve a second major acute stage around four weeks post exposure, known as Katayama fever, typically characterized by fever, urticarial rash, enlarged liver and spleen and bronchospasm (6). The precise pathogenesis of Katayama fever is unknown, and is also frequently missed from diagnosis, hence little is known about potential differential morbidity profiles by parasite species, host or habitat - although it is suspected to involve an immune complex phenomenon initiated by the maturing schistosomes and potentially their eggs. The major chronic clinical manifestations of human schistosomiasis are, however, primarily associated with the species-specific oviposition site of the adult schistosomes. With the female residing, and maturing, within the gynecophoral canal of the larger male, schistosome males carry the pair to the mesenteric plexus (for the intestinal schistosome species - predominantly $S$. mansoni within SSA, South America, the Caribbean and the Yemen, with $S$. intercalatum and $S$. guineensis as minor species within Africa, and S. japonicum or S. mekongi across parts of Asia) or to the veins of the pelvis (for the urogenital species S. haematobium). Sexual reproduction [and in certain cases parthenogenesis (7)] between the gonochoric adults results in the production of up to hundreds or thousands of eggs per day per female worm, depending on the species (on average, 20-200 for S. haematobium (and potentially hybrids therein), 100-300 for S. mansoni, but 500-3000 for $S$. japonicum). Only a proportion of these spined eggs are excreted via the host's feces in the case of intestinal schistosomiasis or urine in urogenital schistosomiasis to pursue the parasite's life cycle. The remainder of the eggs remain trapped in the host tissues inducing granulomatous and fibrotic responses via the host's immune system (8). In children, continued inflammation has been reported to impede, amongst other pathologies, iron metabolism, with consequent disabling systemic morbidities including anemia, malnutrition, physical fitness and impaired physical and cognitive development $(9,10)$.

For urogenital schistosomiasis, long-term chronic infection may lead to lesions in the vesical and ureteral walls, resulting in fibrosis of the bladder and lower ureters, calcification of the urinary tract, and kidney dysfunctions. This chronic inflammation of the bladder can ultimately cause squamous cell bladder cancer (11). Lesions of both the male and female genital tracts, known as genital schistosomiasis, are understood to be potential causes of sterility and maternal fatal hemorrhaging during child birth, as well as risk co-factors for sexually-transmitted diseases such as HIV (11-13). Chronic intestinal schistosomiasis, in its severest form, can cause the development of periportal fibrosis (PPF), characterized by large tracts of fibrotic material laid down along the liver vasculature. With PPF, blood flow through the liver can become restricted leading to the development of portal hypertension, associated collateral vasculature and esophageal varices, and often accompanying ascites. Death can occur through hematemesis caused by the rupturing of esophageal varices $(14,15)$.

Sub-Saharan Africa currently carries the major global burden of schistosomiasis, and hence, since 2003, large-scale mass drug administration (MDA) programmes of praziquantel (PZQ), as preventative chemotherapy (PC), has been implemented across much of SSA (16). Morbidity control has been, in many countries, generally successful (17) and this helped lead to a revision of the World Health Organization (WHO) strategic plan for a vision of "a world free of schistosomiasis", which included controlling morbidity of schistosomiasis by 2020 (defined as prevalence of heavy-intensity infection $<5 \%$ aggregated across sentinel sites) (17, 18). Likewise, the newly-launched revised WHO 2021-2030 NTD Roadmap, aims to eliminate schistosomiasis as a public health problem (EPHP, defined as elimination of morbidity where prevalence of heavy infection intensity is less than $1 \%$ in all sentinel sites) in all endemic countries by 2030 (19). Complete interruption of transmission (reduction of incidence of infection to zero) is also a target in selected African regions by 2030 (19). Likewise, China has set the target of reaching complete interruption of transmission at the country level by 2030 (20). However, recent reports of schistosomiasis being more prevalent than previously thought (21), indications of potentially reduced drug efficacy among populations under high MDA pressure $(22,23)$, continued persistent and/or re-emerging 
'hotspots' of infection (encompassing both operational and biological hotspots), in terms of infection prevalence (17, 24), intensities (25-32) and/or severe host morbidity (33-37) all serve to highlight that schistosomes are highly complex multi-host parasitic organisms for which many essential characteristics of their biology and epidemiology, and the human host response to exposure and infection, remain largely unknown.

One long-standing unanswered question in disease epidemiology in general is why pathogen/parasite prevalence, intensity and associated morbidity are heterogonous across space and time and what factors may be underlying these differences. Host-parasite interactions involve a complex co-evolutionary interplay, where antagonist factors from the host (i.e., defense mechanisms) and the parasite (i.e., infective and/or virulence strategies) play a significant role in determining the outcome in terms of both transmission potential and pathology induced. While host factors and environmental differences have been at the center of most studies trying to understand these disparities, parasite factors, in comparison, have been overlooked. This scenario is certainly true for schistosomiasis for which a key epidemiological feature is that parasite factors are not uniform across space and time. There is substantial heterogeneity in terms of infection prevalence and/or intensity among different geographic areas and individual hosts, even within relatively close locations of the same region (38-41). Likewise, studies have revealed that the disease severity can vary considerably at both the geographical and individual level for both S. mansoni (42-45) and S. haematobium (46-48), associated in part, but not always, in focality to accompanying high transmission and infection intensities (39, 45, 49-52). Epidemiological evidence suggests such variation in morbidity could also be partially explained by, among other factors, the immunological and genetic background of the endemic communities, their nutritional status and/or the length of time individuals have been exposed $(45,53-57)$. However, only a few studies have aimed to assess if potential parasites factors may contribute to this dichotomy in morbidity and particularly in PPF and its complications. In line with the objectives of schistosomiasis control, and the EPHP targets in particular, elucidating the relative etiologies behind such geographical and individual variations in morbidity are of profound importance. Here we review the potential unique parasite factors, human host response factors, and their gene-environment interactions in terms of explaining persisting morbidity hotspots. We then take the situation of schistosomiasis mansoni within the Albertine region of Uganda as a case study in terms of elucidating the potential factors behind the severe morbidity observed to date and the avenues and direction for research currently underway within a new clinical trial programme (FibroScHot).

\section{THE ROLE OF THE PARASITE IN MORBIDITY HOTSPOTS}

By definition parasites are harmful to their hosts, and at its simplest, schistosomiasis-associated morbidity levels have been associated with infection intensity. The recent expansion of
MDA programmes with PZQ has led, in general, to significant reductions in schistosomiasis prevalence, intensity and subsequent human host morbidity $(17,37,58)$. However, it remains to be ascertained how such MDA, together with other anthropogenic selection pressures imposed by our changing world, may impact upon parasite fitness and strategies, nor how this in turn may affect their genetic diversity, transmission dynamics, virulence, clinical outcome and drug resistance development across Africa (59). Early studies in the laboratory have clearly shown that schistosomes with reduced susceptibility to PZQ can be selected for $(60,61)$, but that this resistance comes with a cost in terms of reduced schistosomes reproductive fitness (62) as well as genetic diversity (63-65). Furthermore, within only a few generations, selective pressures imposed on laboratory-bred schistosomes can produce rapid changes in life history traits including parasites infectivity, fecundity, transmission and virulence (66-74). Likewise, field-based studies in which implementation of large-scale intervention trials on optimal treatment in various zones of Africa, have shown a strong variability of response to annual MDA (30). For example, certain villages in the Nile Delta remain highly prevalent to $S$. mansoni despite over two decades of MDA (75). Other locations such as in Côte d'Ivoire have shown an initial decrease in $S$. mansoni infections after MDA sometimes followed by an increase in prevalence the following years (76). Moreover, after multiple rounds of MDA in the transmission hotspots of Mayuge District, Uganda, egg reduction rates (ERR) were found to be reduced to below the WHO recommendation of $90 \%$ in contrast to that observed amongst school-children in similar regions but with a lower past MDA pressure history (22). Assessing therapeutic efficacy of PZQ against schistosomes and the changes in parasites' susceptibility is thus particularly important $(22,23)$. Also in Uganda, the communities on the shores of Lake Albert are a typical example of how despite strong efforts to lower the burden of high infection intensities PPF can remain common $(33,35,77-79)$. Such locations where Schistosoma spp. infection fails to decline in prevalence and/or intensity to expected levels despite multiple years of annual MDA, in comparison to locations that simply have high prevalence before intervention, can be considered as persistent "hotspots" (25-27, 80). As drug resistance is commonly associated with life-history costs (81-84), the potential for drug resistance and associated trade-offs may be important factors in the maintenance of high infection intensities and morbidity levels across Africa. The success, or not, of control strategies in several endemic areas is thus likely to be affected by hostparasite-drug interactions and these associated trade-offs have raised concerns there may be reduced drug efficacy, especially in communities with a more intensive history of PZQ treatment $(22,85,86)$. However, while some degree of reduced drug susceptibility has been suggested $(22,86-90)$, more data are warranted to clarify the evolution of such responses under field conditions and dissect potential resistance from, for example, differential host clearance responses and/or rapid reinfection that seems to best explain apparent low cure rates in most situations (88). 
Additional to potential PZQ resistance, other notable parasite factors may contribute in maintaining high egg outputs and hence potential high host morbidity, despite efficient MDA coverage. Among these factors, density-dependent fecundity compensation, which is a common feature of several microparasite and macroparasite (notably helminths) life cycles may regulate the parasite reproduction and transmission dynamics in a way that make the worm-egg relationship nonlinear (19) and in some cases geographically variable (91). Density-dependent fecundity can either be positive at low levels of infection (e.g. density-dependent facilitation) or negative at high parasite densities (e.g. density-dependent inhibition) because of intra-host competition for resources and/or immunological host responses $(92,93)$. Although still controversial, studies on Schistosoma worm burdens and associated egg counts have shown potential evidence for density-dependent fecundity inhibition in the two major human infecting species, S. mansoni and S. haematobium. The precise nature of the phenomenon is not well understood, since the only direct data that exists is from a limited number autopsy studies (94) and with subsequent biostatistical debate over their original conclusions (94-96). Empirically, population genetic analyses including parentage analysis to estimate the adult worm burden performed on data from Mali $(15,97)$ and Tanzania (98-102) have shown that despite no evidence of a reduction in mean infection intensity (e.g. egg counts) by the standard parasitological techniques (e.g., Kato-Katz), the worm burdens were declining within individual hosts after PZQ administration, thus underlying a relaxation of the densitydependent fecundity inhibition among S. mansoni populations (103). However, comparison of cross-sectional levels of the adult worm derived cationic anodic antigen (an indirect measure of worm burden), against egg counts have shown a diversion from the linear between the measurement, particularly in older individuals, for S. haematobium $(104,105)$ but not S. mansoni for which a linear relationship has been reported (104). These observations raise fundamental questions on schistosome population biology and strongly suggests that, despite a reduction in the adult worm population after treatment, such parasites factors may contribute to population persistence and resilience by producing characteristic epidemiological patterns maintaining the global infection intensities and morbidity to unexpectedly high levels $(106,107)$. Importantly, increasing the reproduction rates of parasites that survive treatment and potentially harbor drug-resistant or virulence related alleles may be expected to increase the spread of such traits in the populations $(106,107)$. Finally, by shaping the transmission dynamics of the parasite and its potential response or resilience to control measures, such processes may complicate both the monitoring and implementation of chemotherapy (103, 107, 108).

Another critical biological parasite factor for consideration is that, whilst disease control programmes, at least in terms of their monitoring and evaluation, tend to consider schistosomespecific morbidity in isolation, parasites under natural situations do not exist in isolation. Inter-genera, inter-specific and even intra-specific interactions are likely and, in many cases, may be predicted to differentially impact the morbidity inflicted upon their hosts via antagonistic or synergistic effects $(109,110)$. For example, across much of SSA, mixed species infections of both S. mansoni and S. haematobium are common (111-115). Such co-infections may lead to co-morbidities with pathological symptoms being a combination between those of the parasite species. A series of studies across Cameroon, Niger, Kenya and Senegal have found that mixed S. mansoni and S. haematobium infections decrease hepato-splenic morbidity compared to single $S$. mansoni infections and increase urogenital morbidity compared to single $S$. haematobium infections $(111,116,117)$. The lowering effect observed on liver morbidity is believed to be because dominant $S$. haematobium males divert S. mansoni females from the portal vein to the vesical plexus, resulting in more eggs being passed through the urogenital tract and less eggs being delivered to the liver tissues. Similarly, in their recent study Huyse and colleagues showed an intriguing association between S. mansoni genetic variation and bladder morbidity (118), again potentially explicable through $S$. mansoni females being paired with $S$. haematobium males that guide females towards the urogenital system (118). In Senegal, ectopic elimination of eggs is also common $(39,89,119-121)$. Distinct studies undertaken there showed that urine samples from people with mixed infections of S. mansoni and S. haematobium contained $31 \%$ (119) and 13\% (121) of S. mansoni eggs. In the latter study people infected with both species and eliminating $S$. mansoni eggs both via urine and via stool had the highest risk of bladder morbidity (121). Likewise, on a same note, Ernould and Sellin found cure rates to be much lower in the Senegalese village with mixed infection compared to villages with single infections (119). The authors found that after treatment S. haematobium infection remained low, whereas egg excretion by $S$. mansoni was seven times higher than at the start of the study. The authors argued that in addition to the possibility of PZQ resistance, or as more likely, potentially higher force of infection/rapid re-infection of $S$. mansoni from the environment at this point, relative to $S$. haematobium, the elimination of S. haematobium after treatment and heterologous pairings allowed remaining $S$. mansoni females to pair with $S$. mansoni males that survived treatment.

Furthermore, with gathering development in molecular typing, and potentially in line with ongoing major anthropogenic changes in the environment, people across large expanses of, particularly Western, Eastern and Southern SSA, have been found to be infected with viable hybridized schistosomes involving the human urogenital $S$. haematobium with the intestinal schistosome species of livestock S. bovis, S. curassoni, S. mattehii and beyond $(21,122-127)$. Given the pairings of urogenital with intestinal schistosome species here, we may well predict similarly differential morbidity profiles as that observed for the aforementioned S. mansoni with S. haematobium (114, 128). Indeed, given that these Haematobium group hybrids produce viable eggs, in contrast to the more phylogenetically distant $S$. mansoni with $S$. haematobium pairings, one may predict exacerbated differentiating morbidity profiles in relation to 
infection status (129). Hybridization between genetically distinct species raises the possibility of promoting genetic admixture and diversity, introducing novel genes across species boundaries, but also lead to the emergence of novel hybrid zoonotic strains with an increased transmission potential that could have serious implications for the control of the disease (124, 129-131). The differential impact of such inter-specific interactions on the host morbidity profiles observed are pertinent in terms of highlighting the need to, wherever possible, measure both hepatic and urogenital morbidity indicators during MDA monitoring and evaluation where co-infections and zoonotic species are known or suspected to exist.

The role of intra-specific differences and interactions on the host morbidity profile must also be considered $(132,133)$. Although the role of the parasite genetic diversity in differential host response is well known for microparasites $(134,135)$, there is comparably less known regarding the potential importance of macroparasite genetic heterogeneities in general, and schistosomes in particular, on disease epidemiology (136). Laboratory studies, however, have shown that schistosomes strains or populations from the same or different geographical locations can show a number of differences in biological traits related to transmission and virulence such as infectivity, egg production, pathogenicity and response to chemotherapy $(11,137-146)$. For example, some S. haematobium strains studied in the laboratory show different levels of mortality and worm recovery in hamsters as well as differences in snail infectivity (147), while different S. mansoni strains have been shown to induce disparate rates of hepatomegaly and splenomegaly despite comparable fecal egg counts (137). Moreover, alternative transmission strategies with the occurrence of trade-offs between parasite transmission and host survival have been observed in genetically different schistosome populations (148). Hence, this shows that schistosomes' virulence occurs with significant variation for both intermediate and definitive hosts on a genotype-dependent basis, demonstrating that virulence and transmission may vary across individuals of a population and/or between populations $(66,140,148)$.

Species-specific microsatellite markers developed for $S$. mansoni (149-152) and S. haematobium $(103,153)$ have also provided a better understanding of schistosomes epidemiology and transmission patterns through investigation of genotypic associations at the population level in the field (154). Such studies have revealed considerable variation in schistosome populations with high levels of genetic diversity mainly finding its origin at the infrapopulation level (41, 152, 155-163). Schistosomes are mostly structured according to distance between transmission sites with limited gene flow at both a regional and continental scale $(65,157,164)$. However, patterns of population structure vary between different regions and epidemiological settings (165) and while some studies show that the parasite's genetic variation is usually randomly distributed at relatively small scales with high levels of gene flow within and between hosts and sites $(89,154,156,163,166$, 167), others show that some populations may be significantly differentiated even among relatively close geographic locations (41, 160, 168, 169). In Uganda, for example, evidence suggests that parasite population genetics are potentially playing a role in the variations in morbidity found between Lake Albert and Lake Victoria. In addition to disparate levels of morbidity with higher levels of PPF in Lake Albert communities, previous barcoding of S. mansoni collected from both definitive human hosts and intermediate snail hosts on the shores of Lake Albert in Uganda and Lake Victoria in Kenya, Tanzania and Uganda revealed that the population genetic structure of $S$. mansoni is not uniform across the endemic area. Whilst both populations are extensively diverse, studies showed that in Lake Victoria nonsynonymous mutations were more diverse than in Lake Albert and that there was a strong genetic differentiation between the two parasite populations $(167,169-173)$. Interestingly, other studies have shown that parasites from Lake Victoria area present different local strains (173), with the relatively highest levels of genetic diversity across several markers (22, 155, 157, 174). The epidemiological heterogeneity of intestinal schistosomiasis between these lake environments could thus be due to parasite diversity itself $(117,172)$ and the lack of gene flow strongly suggests that any locally evolved traits, such as virulence or putative drug resistance would likely stay restricted to the focal population, leading, at least in part, to differential host morbidity. Previous studies conducted in Mali, Senegal and Uganda have, however, found no associations between infection intensity and parasites genetic diversity when comparing allelic richness, heterozygosity, nor parental genotypes to various levels of infection intensity (103, 156, 167). Nonetheless, the parasite's virulence measured through its fecundity could in part be linked to the parasite's genetic diversity or associated to a particular genotype. Although few potential direct links between parasite genetics and host induced pathology are to yet be made, various authors have suggested that schistosomes infection intensity and the parasite populations' genetics in different African countries may be responsible for such discrepancies in clinical outcomes by acting on several parasite features including their fecundity and immunogenicity $(53,132,166,175,176)$. Nevertheless, our knowledge on the role of parasite genetic variation in host disease phenotype in human schistosomiasis is currently limited and only few studies have directly investigated the relationship between morbidity and the genetic variation.

Brouwer and colleagues (133) gave the first insight in this delicate host-morbidity/parasite-genetics association by focusing on $S$. haematobium, the species responsible for urogenital schistosomiasis. Using randomly amplified polymorphic DNA (RAPD) between S. haematobium populations from children with varying pathology of urinary tract in Zimbabwe the authors compared the distribution of S. haematobium genotypes in the definitive host in relation to that of the clinical outcome (133). They showed that the allelic frequencies at eight loci differed significantly between the mild and severe groups and that three clusters were significantly over-represented in schoolchildren with severe urogenital lesions. Inspection of allelic distributions for clusters revealed that cluster 1 (severe) and cluster 7 (mild) had inverse genotypes at loci that differed significantly between groups, supporting the notion that particular parasite strains or genetic 
factors may be associated with clinical outcome. However, they could not robustly link pathology to parasite genotypes or genes due to the limitations of the RAPD technique. Further studies were therefore conducted on S. haematobium with the aim of elucidating any potential relationship between host morbidity and parasites genetic variation. In a second study, while the authors found high levels of genetic diversity among the three isolates studied (Egypt, Zimbabwe, and South Africa) they did not identify a role of parasites genetic diversity in the difference in morbidity observed (132). Finally, in a third study, the same authors used the RAPD based-approach in Sudan, but found no association between abnormal ultrasound urinary tract scans and intensity of infection (177) nor could they identify any significant difference when comparing the three different genotypes identified with the severity of the disease (178). However, the authors suggested that differences in parasite strains, such as infection intensity, could partially explain why they failed to retrieve similar results to those previously observed by Brouwer in Zimbabwe (133), together with the small number of variable alleles recorded in their study largely hampering their ability to detect associations between diversity and host morbidity.

In S. mansoni, at least three studies have been conducted on host characteristics and putative parasite genetic variation. In the first one, Barbosa and colleagues (179) used 15 microsatellite markers and found geographic clustering in S. mansoni over a scale of $8 \mathrm{~km}$. However, the authors could not link this with demographic or epidemiological host characteristics (179). A second study using 11 microsatellite markers (41), suggested the existence of a link between parasite genetic diversity and prevalence and intensity of infection between three settings. The authors observed that the gradient they found in genetic diversity was the same as the gradient they previously observed when focusing on the parasite prevalence and intensities of infection. However, because only three populations were sampled, they could not statistically validate this link between parasite genetic diversity and parasite virulence (41). Finally, Huyse and colleagues are to date the only ones to have formally demonstrated a potential link between the parasite genetic variation and host disease phenotype in humans (118). Using nine microsatellite markers on 1561 S. mansoni larvae collected from 44 human hosts in Senegal they were able to link host characteristics such as age, sex, infection intensity, liver and bladder morbidity to the parasites genotypes. They showed a significant association between allelic variation at the parasite locus L46951 and host infection intensity and morbidity. This locus is located near a gene (cGMP-dependent protein kinase) linked to schistosomes egg production. Furthermore, by reconstructing the parental genotypes the authors suggest that adult parasite populations with the allele L46951 have a higher fecundity and therefore produce more eggs and offspring than those without this allele, thus potentially inducing higher levels of morbidity (118).

Despite scarce studies and some contradictory results, or at least issues in the methodology and detection power hampering the authors' ability to link parasites genotypes with host characteristics, these studies clearly highlight the importance of genetic variation as an additional factor to schistosomiasis host disease phenotypes, including a potential association with persistent hotspots. It is necessary to take into consideration parasite genetics and population diversity in future epidemiological studies to make a clear relation between transmission and morbidity in different geographical zones where particular parasite genotypes may be predicted to interact differentially with their host and lead to differences in morbidity. One of our greatest limitations to date is the absence of genetic markers sufficiently powerful to accurately allow us to identify and link regions involved in the parasite's virulence or fecundity with host morbidity indicators. Such data may be valuable in monitoring relationships between the parasite's transmission (prevalence and intensity) and virulence with particular parasite genotypes or degrees of genetic diversity in clinical phenotypes. Nevertheless, since microsatellites are neutral markers, they are not expected to identify such parasites traits unless they are physically close to such genes. One potential first step would thus be to properly define and find a consensus on what should be considered as parasite virulence factors in schistosomes and other macroparasites of medical and/ or veterinary interest, while a second fundamental step would be the development of specific virulence/fecundity markers or whole genome Single Nucleotides Polymorphism (SNP) markers allowing us to address the challenges at the interface between parasite genetic factors and host induced morbidity.

\section{THE ROLE OF THE HOST IN MORBIDITY HOTSPOTS}

As stated above, a key epidemiological feature of schistosome infection is that the parasite prevalence, infection intensity and associated morbidity are not uniform across space and time, with substantial heterogeneity among different geographic areas and individual hosts even within relatively close locations of the same region $(40,41)$. In addition, familial aggregation suggests that host-intrinsic and not just behavioral factors can be involved in development of severe morbidity in humans $(180,181)$. There have been a number of studies convincingly demonstrating that genetic factors are important within intermediate snail hosts in terms of their susceptibility and/or subsequent morbidity to schistosomiasis and in promoting heterogeneity in patterns of infection (see $(71)$ and $(182,183)$ for review). In Uganda, for example, a fundamental factor of differing snail host populations could drive differing transmission dynamics of $S$. mansoni between Lake Albert and Lake Victoria, with prevalence levels and reinfection rates higher at Lake Albert $(170,184)$. Indeed Biomphalaria stanleyi is found only in Lake Albert, and $B$. choanomphala is present only in Lake Victoria, while $B$. sudanica and B. pfeifferi are present in both lakes (185-189). Such intermediate host-specific factors could have influenced the evolutionary history of the parasites, playing an important role shaping the genetic composition of schistosome populations (156, 174, 190, 191) and selecting for particular parasite genotypes of varying virulence. 
Direct evidence from the definitive hosts, and the human host in particular, is in contrast less available due, in part, to an inherent inability to perform controlled studies. Our knowledge of the host intrinsic (rather than behavioral factors) underlying disease dynamics and mechanism are therefore accumulated from autopsy and observational epidemiological studies that are clinical, genetic or immunological in design; combined with animal experimental models for which the evidence is heavily skewed towards $S$. mansoni due to the existence of a well-established murine model for this infection. The mouse is not permissive to $S$. haematobium, with hamsters being utilized for lifecycle maintenance. This, coupled with a differing $S$. haematobium predilection site within the hamster (the blood supply of the intestine, rather than of the venus-plexus of the pelvis as in humans) has resulted, until the introduction of a murine egg micro-injection experimental model $(192,193)$, in a relative scarcity of evidence for the immunopathological mechanism in S. haematobium infection. Without knowledge of the underlying mechanisms of severe morbidity, relating variation in host factors across a geographical scale to indicate the presence of morbidity hotspots is not possible.

Our early understanding of much of the clinical syndrome of human intestinal schistosomiasis was gained through the ground breaking autopsy work conducted by Alan Cheever and colleagues in the 1960s in Brazil. Due to the host blood flow, in $S$. mansoni infection a large proportion of the eggs laid by the female worms get trapped in the distal site of the liver. In all cases of liver PPF observed by Cheever $(n=105)$, infection with $S$. mansoni was present, and amongst the cases $85 \%$ had varices, and hematemesis through rupturing of esophageal varices was the main cause of death (14); thus establishing S. mansoni as the causative agent of PPF and its consequences. In addition, after perfusion of the cadavers he concluded that worm burden was positively associated with presentation with PPF and its complications (15). Cheever did, however, warn that any observations made within his autopsy studies may not reflect the epidemiological patterns observed within populations of endemic areas as the demographic profile of autopsy cohorts are by their inherent nature skewed towards the older sections of the human population and/or those with severe disease who died young. Repeat autopsy studies conducted in Egypt where $S$. mansoni and $S$. haematobium are endemic confirmed the linkage between PPF and intestinal schistosomiasis through presence of $S$. mansoni eggs within macroscopic PPF lesions of the liver, and discounted a link with S. haematobium (194).

At the time of the autopsy studies, clinical palpation of the liver and spleen were the standard method of assessing whether an individual had severe schistosomiasis. It was therefore not until the 1980s and the introduction of portable ultrasound machines that researchers were able to establish the true relationship between presentation with PPF and demographic and infection related parameters. A dissociation between peak infection levels and peak prevalence of PPF was observed, with fibrosis more apparent in adults than in adolescents, the age group who carry the greatest infection burden $(53,195,196)$. Duration of ongoing infection, as well as high transmission levels, are now known to be important in the development of PPF and its severity upon assessment (33). As adults, particularly males, are more likely to have severe PPF (53), and this is linked more to past exposure than current infection, treatment studies with PZQ, which reduces infection burden but does not directly treat the fibrosis, have shown that regression of PPF is less likely to be observed amongst this demographic (197-199). In children, on the other hand, PPF is often mild, but clearly observable by ultrasound, and can respond well to treatment. Amongst children regression of PPF can be observed through a reduction in severity score at 7-months post-treatment (200), with full resolution being observable by 2 -years post-treatment (201). However, the success of treatment of PPF is also dependent on the force of transmission, with the rapid reinfection that can occur in high transmission areas impeding the success of treatment (199).

In contrast to $S$. mansoni where severe morbidity occurs in tissues distal to the site of predilection, in S. haematobium the immediate sites of egg deposition are those associated with severe morbidity. S. haematobium worms pairs are believed to be relatively sedentary, so the resulting tissue inflammation is very focal, leading to bladder wall thickening in areas where eggs are deposited regularly $(97,202)$. It has been proposed that there is no pattern to where in the bladder the lesions occur (203). Interaction between responding immune cells and the neighboring urothelial cells causes urothelial hyperplasia (202), which, with time, can result in the development of ultrasound detectable masses (defined as $>1 \mathrm{~cm}$ thickening of the bladder wall) and pseudopolyps (204). Younger children mostly have what has been defined as milder bladder pathology, characterized by wall thickening or irregularities (205). These irregularities are likely to represent early polypoid lesions, which in autopsy studies were observed around live eggs so indicative of active infections prior to the death of the younger cadavers (202). In epidemiological studies, a strong predictor (though not a conclusive marker) of bladder morbidity, particularly in children, is infection intensity (206-208). These bladder wall irregularities therefore resolve in a manner similar to, but more readily than the resolution of mild PPF after treatment with PZQ, with full resolution observable within 6-months (205, 209, 210). However, again similar to $S$. mansoni associated morbidity, in high transmission areas the success of a single round of treatment is impeded by rapid re-infection and the associated re-emergence of ultrasound detectable morbidity within a year $(205,209,210)$. In contrast, upper urinary tract morbidity resolution post treatment is less successful (205).

The immuno-pathology secondary to schistosome infection is thought to be as a result of host immune responses to egg antigens rather than direct damage to the tissues by the eggs. It is thought in S. mansoni infection that the arising tight granuloma formation, characterized by concentric rings of encapsulating immune cells around the eggs and subsequent collagen deposition, may lead to advanced hepatosplenic schistosomiasis $(1,11,143,211)$. Murine studies show that granulomas formed during S. mansoni infection are as a result of T helper (Th) 2 cytokines produced by $\mathrm{CD}^{+} \mathrm{T}$ cells (212). 
This results in the recruitment of immune cells including eosinophils, monocytes, alternatively activated macrophages, basophils, T and B cells to the site of inflammation (213), and is aimed at containing the eggs and their hepatotoxic products (214-216). How these early granuloma responses relate to the long-term consequence of PPF observed within humans with intestinal schistosomiasis remains largely unknown. In addition, despite the egg micro-injection murine model of S. haematobium morbidity indicating similar granuloma formation in response to the eggs of this species, there are very significant biological differences between $S$. haematobium and S. mansoni, including the absence of a $S$. haematobium $\Omega-1$ homologue (216), a major immunogenic glycoprotein secreted by $S$. mansoni eggs that drives Th2 polarization by dendritic cells $(217,218)$. The experimental data from S. mansoni egg immuno-biology is therefore not directly transferable to $S$. haematobium eggs.

At the human host genetic level, polymorphisms in the interleukin (IL) -13 gene have been associated with susceptibility to S. haematobium infection (219) and the loci of the IL-13 gene, 5q31-q33, has been associated with susceptibility to S. mansoni infection (220). However, care must be taken in differentiating a type-2 response associated with protection from infection per se, which is more significantly linked with immune responses to adult worm derived antigens ( (221) for review), from those responses that arise to egg antigens and cause morbidity. That said, in line with the evidence from murine studies that Th2 cytokines produced by $\mathrm{CD} 4^{+} \mathrm{T}$ cells induce granuloma formation, human clinical-immunological studies have found PPF to be associated with sustained Th2 responses (222). One suggested mechanism for fibrosis from nonschistosome human studies is the Th2 cytokine-induced differentiation of $\mathrm{CD}_{1} 4^{+}$monocytes into fibrocytes (223). Whether this is occurring in the context of schistosome infection is not known. In humans, we have shown that Th2 responses to $S$. mansoni egg antigens in adults from a fishing village in Uganda (224) and school-aged children in Kenya (225) are generally suppressed during active $S$. mansoni infection. A study by Colley et al. (226) suggests that dysregulation of T-cell responses may be causative of PPF. However, this study was based on $\mathrm{T}$ cell expansion assays and does not mention the type of $\mathrm{CD} 4^{+} \mathrm{T}$ cells that is involved. In support of the "dysregulated Th2" hypothesis, several human studies in Brazil where PPF was defined using ultrasound have indicated an important role for interleukin (IL)-13 in its development with elevated IL-13 levels in response to $S$. mansoni soluble egg antigen (SEA) observed amongst individuals with PPF (227-229). The association of Th2 cytokines with fibrosis and much of the pathology following $S$. mansoni infection has also been shown in murine studies of schistosomiasis (230-232). IL-13 is thought to induce its fibrogenic effects through the activation and production of transforming growth factor (TGF)- $\beta$ (233), though TGF- $\beta$ independent mechanisms have also been suggested by studies using murine models (233). Experiments using the S. mansoni murine model have also shown that these type-2 immune responses are under epigenetic control with modulation of dendritic cells towards those that polarize T cells to type 2 (234), polarization of the $\mathrm{T}$ cells themselves (235), and alternative activation of macrophages (236) all being controlled by epigenetic modification. For macrophages, prior exposure to $S$. mansoni increased the expression of the demethylase that promoted alternative activation of macrophages (236), suggesting this response may be exacerbated when infection is prolonged.

Information from an autopsy study conducted in Ibadan, Nigeria also implicates a type-2 response in S. haematobium morbidity, though histologically a stage progression in lesion is found between children and adults (202). The early polypoid lesions, representing active infections in younger cadavers (mean age of 13-years), are characterized by loose granuloma formation around clusters of eggs with mass eosinophil infiltration, a cell type commonly associated with type 2 responses, particularly IL-5. In older individuals, lesions have more distinct mature granulomas, concentric circles of fibrosis and collagen deposition, more in line with the histological appearance of granulomas in the egg micro-injection model. When dissected these lesions have a "gritty" sensation, leading to the term "sandypatch". They appear to be a chronic manifestation often being associated with calcified eggs. A similar progression from loose eosinophilic lesions, in this case termed rubbery papules, to sandypatches is observed in female genital schistosomiasis (237). Epidemiologically, leukocyturia, a symptom of S. haematobium infection, is highly correlated with egg counts $(238,239)$ and amongst a cross-sectional Sudanese cohort, 59\% of individuals had eosinophiluria (defined as $>=5 \%$ of urinary leukocytes). A disparity between urinary and circulating cell differential counts, with a mean of $42 \%$ of urinary cells being eosinophils, indicates that urinary eosinophils were tissue eosinophils shed into the urine. Eosinophiluria, but not other leukocyte counts or microhematuria prevalence, mirrored infection intensity (240), again emphasizing the role of the eosinophil within active $S$. haematobium bladder lesions. Eosinophil effector mechanisms include release of the toxic substances eosinophil cationic protein (ECP), eosinophil derived neurotoxin and major basic protein from granules. Urinary ECP levels in schoolchildren can differentiate between severity of bladder morbidity with a greater sensitivity than egg counts and as ECP levels are higher in infected schoolchildren without ultrasound detectable morbidity, than non-infected school-aged children, ECP is also a marker of early bladder wall inflammation (210). In addition ECP levels reflect resolution and re-emergence of bladder morbidity after treatment (210). Finally, ECP detection in vaginal lavage fluid is indicative offemale genital schistosomiasis (FGS), with levels being higher for individuals with rubbery papules (241). The role of eosinophils in FGS is also indicated through decreasing vaginal lavage levels of ECP after treatment (242). In school-children low ECP levels prior to cell lysis, in comparison with potential cellular release as measured after lysis (243), suggest that eosinophils may not solely play traditional effector roles in response to $S$. haematobium eggs. Eosinophils are multi-functional immune cells, capable of antigen presentation and immune skewing and regulation by selective release of cytokines (244). Eosinophils are 
also a key component of the $S$. mansoni granuloma, and a significant association between a polymorphism within the ECP gene and presentation with PPF amongst the inhabitants of a Lake Albert fishing village has been observed, but this observation was dependent on the ethnic group of the human host (245).

In competing theory to the type- 2 responses discussed above, a role for the pro-inflammatory cytokine tumor necrosis factor (TNF) in hepatic fibrosis and severe schistosomiasis disease in humans has been demonstrated by several studies. The first study to show a link between TNF (early studies do not clarify the member of the TNF family measured) and hepatic fibrosis was in Brazil (246). This was a hospital-based study and adult patients were categorized as hepatosplenic using clinical definition, rather than ultrasound. Further studies of community research subjects affirmed the association between elevated levels of TNF and increased risk of hepatosplenic disease (247-249). However, how the mechanisms behind PPF can differ between the sexes as reported in the Booth et al. study (247), with high TNF levels being associated with PPF in adult females but not males, is currently not clear. While the study of Mwatha and colleagues (248) was based on clinically rather than ultrasound classified school-aged children in Kambu region of Kenya, where a later study demonstrated hepatosplenomegaly in school-aged children in the absence of PPF (250). When immune responses of the children participating in the later study were examined, there was also high measurable TNF in response to SEA stimulation. When re-infection was abrogated through annual treatment and mollusciding of the river where transmission occurred, the TNF response to SEA diminished significantly (251). This raises the question as to whether TNF is a response to infection per se as opposed to part of the immuno-pathological disease process that leads to the development of PPF. We cannot know if the Kenyan children in the study of Mwatha and colleagues or the later study would have gone onto develop ultrasound detectable PPF. That said, studies in murine models have shown TNF to be an important mediator of granuloma formation and hepatic fibrosis (252), however, clear distinction between granuloma formation and PPF has to be drawn as we do not know how the two relate. Host genetic studies are contradictory regarding SNPs within the TNF loci; with no observable association between HLA-TNF polymorphisms and presentation with PPF in two Sudanese populations (253), but an association between a TNF gene SNP and PPF being reported for a Brazilian population (254). High TNF-alpha levels in response to SEA stimulation have also been shown to be associated with ultrasound detectable bladder morbidity due to S. haematobium infection in Kenyan case-control (255) and cross-sectional studies (256).

In stark contrast to the role for type- 2 cytokines and TNF in fibrosis, community-based studies in Sudan (249) and Uganda (57) have associated high levels of interferon (IFN)- $\gamma$ with reduced risk for fibrosis. In addition linkage between polymorphisms in loci closely linked to IFN- $\gamma$ receptor genes (57) and in the IFN- $\gamma$ gene itself (249) with PPF have been reported. Non-schistosome experimental murine studies support this anti-fibrotic activity of IFN- $\gamma(257)$ and have associated it with modulatory effects of IFN- $\gamma$ on TGF- $\beta$-induced immunopathology (258). Murine studies of schistosomiasis have associated IFN $-\gamma$ with reduced infiltration of cells into the granulomatous sites and thus modulating the size of the granuloma (259). However, a further murine study of schistosomiasis has associated high IFN- $\gamma$ levels with severe liver pathology during S. mansoni infection (260). In this study, mice that lacked IL-10 and IL-4 manifested mortality within few weeks of infection with S. mansoni, demonstrating that a balanced immune response, that is appropriately regulated, is what is required to limit pathology. In humans, Schistosoma haematobium infection has been shown to lead to hypermethylation of immune system genes within CD4+ T cells, with inhibition of genes in the Th1 and IFN $\gamma$ signaling pathways being observed, indicating a role for epigenetic control of the IFN $\gamma$ response. This inhibition was shown to persist 6-months after treatment (261).

Granuloma size in schistosome-infected animal models has been shown to peak between 6-9 weeks after infection, after which time they spontaneously regress in size $(262,263)$. In experiments where spleen, lymph node and $\mathrm{T}$ cells were adoptively transferred from chronically infected mice, granuloma size was shown to be reduced in the recipient animals $(264,265)$. From these experiments, it is apparent that the spleen and lymph node cells play an important role in the immunoregulation of granuloma formation. A role for B cells and their Fc $\gamma \mathrm{R}$ (IgG receptor) in the immunoregulation of the granuloma has been previously reported (266-268). Chronic schistosomiasis has also been associated with increased frequencies of FOXP3 + T regulatory (Treg) cells, and a role for Tregs in the control of morbidity during S. mansoni infection has been reported in both human and murine studies. A study of community members in Kisumu, Kenya reported increased frequencies of Treg cells in adults infected with S. mansoni (269) while treatment of S. haematobium infection amongst Gabonese children resulted in a decrease in Treg cells indicating that their numbers are supported during active infection (270). In another Kenyan study, the removal of Tregs from PBMCs donated by S. mansoni-infected individuals was associated with reduced levels of the key regulatory cytokine IL10 (271), supporting the notion that Tregs are one of the sources of IL-10 and their immunoregulatory function is partly mediated by this cytokine. The removal of Tregs from SEA stimulated PBMC cultures of $S$. haematobium infected children increased the production of type-2 and pro-inflammatory cytokines (270). In a further study of $S$. haematobium infected school-children, B regulatory cells were shown to be important in inducing the expansion of IL-10 producing T cells (272). Booth et al. reported an association between low IL-10 scores following stimulation of blood with schistosome antigens and PPF in children from a community at Lake Albert in Uganda (247). While Kenyan study participants with high levels of TNF-alpha associated with bladder morbidity also had low levels of IL-10 (255, 256). Studies in murine models of schistosomiasis have supported these observations by demonstrating increased proportions of 
Tregs following infection of mice with S. mansoni or injection with SEA (273-276). The importance of Tregs in the control of immunopathology during $S$. mansoni infection has further been demonstrated by adoptive transfer of purified CD25-depleted T $\mathrm{CD}^{+} \mathrm{T}$ cells into mice without mature $\mathrm{T}$ and $\mathrm{B}$ cells. This depletion of CD25 $\mathrm{CD}^{+} \mathrm{T}$ cell (including Treg cells which express high levels of CD25) resulted in severe disease in these animals (275). The Tregs perform their immunoregulatory functions through IL-10-dependent and IL-10-independent mechanisms. The suppression of $\mathrm{CD}^{+} \mathrm{T}$ cell expansion and egg-induced Th1 responses by IL-10-producing Tregs has been reported in murine models of schistosomiasis (276). However, IL-10-independent mechanism of down-regulation of Th2 responses has also be reported (277).

Another aspect of the host that may be pertinent to the persistence of disease despite multiple rounds of treatment are variations in the pharmokinetics (PK) of PZQ; the subject of a recent systematic review (278). The authors of the review note that, whilst no pharmacogenetics studies have apparently yet been carried out for PZQ, SNPs in cytochrome P540 enzymes have been hypothesized to result in differing PK of PZQ. In the context of morbidity hotspots, differences in PK will not directly lead to development of morbidity, only indirectly acting through persistent infection, so parasite and other host factors will still be of the utmost importance. Regarding whether or not PK can change with increasing number of treatment rounds of PC impacting on its effectiveness, the authors of the systematic review make no note of acquired changes to the PK of PZQ. They do, however, raise the impact of liver morbidity on PZQ metabolism. The source paper (279) showed decreased metabolism of PZQ with increasing Child-Pugh scores of liver function (based on laboratory and clinical criteria, rather than ultrasound), though no difference in the cure rates between individuals with varying liver pathology were found. As ultrasound for PPF was not undertaken and a significant number of the cohort had positive makers for co-infection with viral hepatitis (85\% for Hepatitis B and 99\% for Hepatitis C), the impact of schistosomiasis mansoni morbidity on PK of PZQ remains largely unknown, but it certainly raises the question of whether co-infection with active viral hepatitis impacts on schistosomiasis treatment efficacy.

Overall, regarding host intrinsic factors, one may suspect that for genetic predisposition to result in a morbidity hotspot would require greater carriage of the predisposing profile within the population not just at the individual level. To date, human genetic studies have been conducted within populations, with some repeat association studies conducted in other populations, but to our knowledge no widescale genetics studies comparing susceptibility across populations has been conducted. We do know that within Lake Albert fishing communities that had high prevalence of PPF prior to MDA, that the Bugungu (ethniclinguistically Bantu) and Alur (ethnic-linguistically Nilotic) people, despite differing ECP polymorphism linkage with morbidity (245), did not appear to have differing overall susceptibility to morbidity (33). This suggests no population level differences in susceptibility between these two ethnically diverse groups within this morbidity hotspot and perhaps indicates that genetic predisposition of the host may be more important in the manifest outcome of a morbidity hotspot i.e. who within the hotspot develops morbidity rather than being the underlying cause of the hotspot itself. The same would be true of genetic influences on PK of PZQ, with an influence on who within the population responds best to treatment, with greater potential for resolution of morbidity, rather than on the maintenance of the morbidity hotspot itself. Epigenetically, perhaps there could be some argument that past exposure/ exposure of previous generations could predispose a population to mounting responses that are associated with the development of morbidity. However, contrary to supporting long-term epigenetic modifications passing from mother to child that result in increased morbidity within a population, murine in utero exposure to $S$. mansoni leads to a significant decrease in acetylation of the IL- 4 promotor, reducing type- 2 responsiveness of naive $\mathrm{T}$ cells of the offspring (280). There are not, to our knowledge, any published studies examining the potential relationship between epigenetics and schistosomiasisassociated morbidity in the human host.

\section{THE ROLE OF HOST-PARASITE- ENVIRONMENTAL INTERACTIONS IN MORBIDITY}

From the combined knowledge derived from autopsy and epidemiological studies it is clear, for both $S$. mansoni and $S$. haematobium infections, that longevity of exposure to the egg antigens results in progression of fibrotic morbidity and that particularly amongst adults this can result in chronic, extensive fibrosis that is hard to treat through PZQ alone. It is also clear that key to the development of severe disease, particularly for PPF, is the breakdown of the regulation of the immune responses elicited against the egg antigens of the schistosomes. This regulation is imperative in protecting host tissue but also allows the parasite to sustain chronic infection by limiting damage to their host, and thus passage of its genetic material to future generations. It is therefore important to note that besides direct damage induced by the worms and their eggs, an aspect of helminths virulence is that they have evolved sophisticated mechanisms allowing them to evade or manipulate their hosts' immune response and thus sustain a chronic infection. Helminths' masterful manipulation of the immune system has mostly been characterized from murine experimental models of nematode infections and is mainly attributed to their secretomes and the variety of immunomodulatory products interacting with host tissues at every phase of the host immune response (281). This ability/inability to induce immunomodulation could thus be assimilated to virulence factors as defined in microparasites. As discussed, it is clear that regulatory immune cells and cytokines are induced during schistosome infection. Although not necessarily as well characterized as some of the immunomodulatory molecules secreted by nematodes, it is known that schistosome egg derived molecules, such as $S$. mansoni antigen IPSE/alpha-1, can induce 
expansion of regulatory B-cells, though this was concluded not to be the sole molecule within SEA that has this capability $(276,282)$. Although much work is needed to further characterize such factors in macroparasites in general and in particular for schistosomes, an interesting open question is to know whether such immunomodulatory molecules may vary at the parasite population level and across geographical zones, hence playing a role in persistent hotspots of infection and morbidity.

The complexity and multifactorial dimension of schistosomes transmission including host factors (behavior and water usage, genetics, age, sex and susceptibility, compliance to taking the drug); site-specific factors (sanitation, and type of water contact, or locations) as well as intermediate host factors (abundance, strain, species); but also differences in parasites factors (species and strains, parasites genotype and diversity, parasites ecology) and parasites interaction (co-infection, competition and hybridization), are all fundamental to our comprehension of schistosomiasis disparities in morbidity and persistent hotspots identified across the African continent (Figure 1). In these times of global changes and extensive human induced selective pressure, it is worthwhile considering that the parasite's evolutionary history may be undergoing substantial modifications affecting their genetic diversity, transmission dynamics, virulence, and drug resistance development across Africa (59), with some potential implications for schistosomiasis clinical outcome and control. In this context, persistent biological hotspots and the failure of control strategies in several endemic areas is likely to be affected by host-parasiteenvironmental interactions and associated trade-offs such as increased virulence in parasites. To date we cannot rule out variable drug effectiveness, reduced efficacy and drug resistance, nor an increase in any specific genotypes/genotype combinations that are associated with increased virulence and persistent morbidity. Although such modifications can be monitored through the integration of clinical and parasitological measures with population genetic analyses using microsatellite markers, it is also important to point out that the small number of neutral genetic markers used in most studies and the fact that they do not span the entire genome may be poorly resolutive in comparison to whole-genome sequencing approaches. Therefore, if only a few alleles were to be involved in the parasite's life history changes, there is a strong possibility that changes in allele frequency at the population level would not be detected by such methods. Indeed, although some parasite individuals may contain a few alleles responsible for resistance or other virulence related traits they may not cluster together because the majority

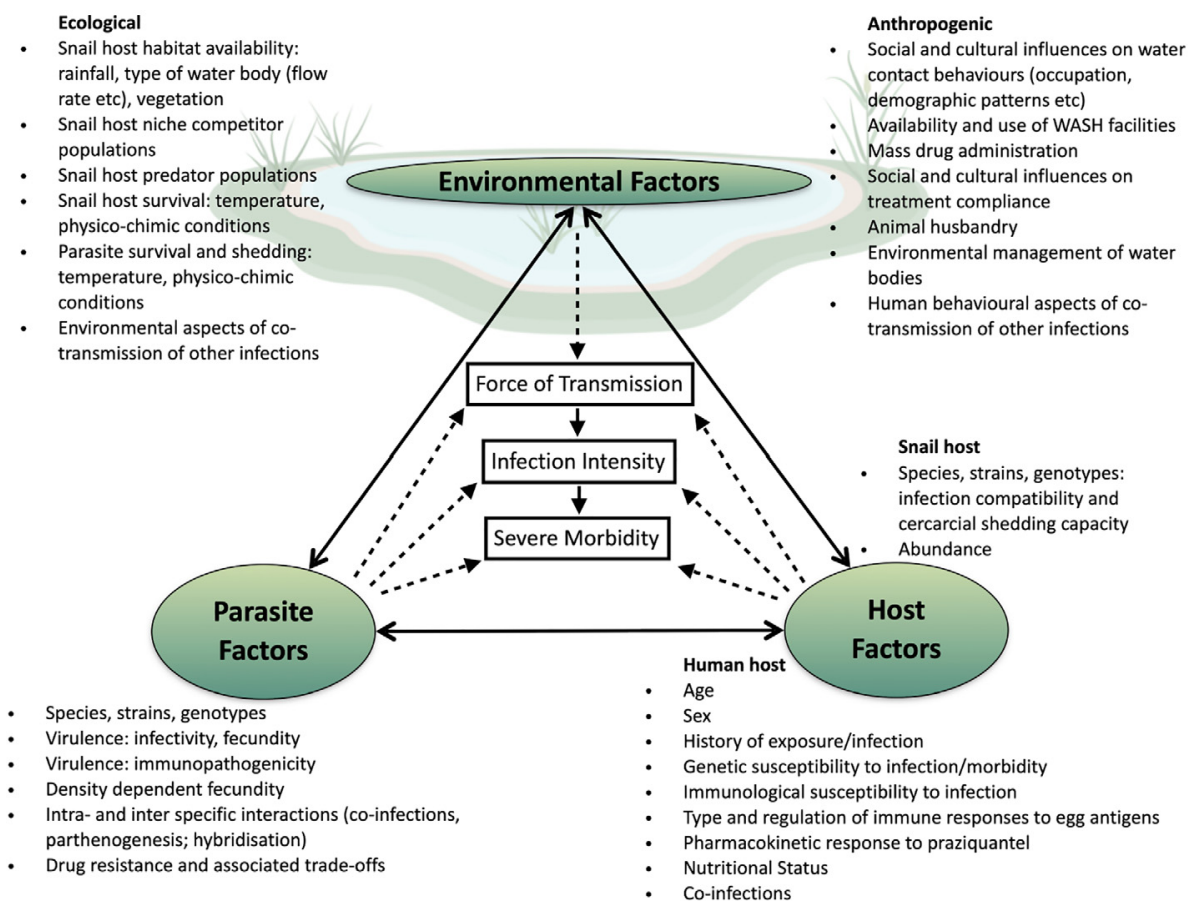

FIGURE 1 | Potential drivers of persistent transmission and morbidity hotspots. Within the center of the transmission triangle are three elements known to be directly linked (solid arrows): force of transmission from the snail to human host is directly related to accumulation of infections over time and thus an increase in intensity of infection as measured by egg excretion; in turn high infection intensity is a known (but not sole) factor in the development of morbidity. Force of transmission of Schistosoma species is influenced by interactions (dotted arrows) between environmental, parasite and host factors. Once within the human host further interactions between parasite and host will determine the successful accumulative establishment of adult worm pairs and the fecundity of those worm pairs. Further interactions between the parasite and host will influence whether the host will develop severe morbidity. While interactions between environmental, parasite and host factors combine to drive up the force of transmission resulting in hotspots, these factors do not exist in isolation of each other, with direct influences from one corner of the transmission triangle to another occurring. 
of other alleles may vary at the individual level in the infrapopulation or component population. Furthermore, because cure rates are not $100 \%$ effective (85), it is worth considering that not only resistant parasite may be found after treatment, bringing some additional background noise into the genetic analyses. The continuous gene flow between human and animal parasite populations that undergo different selective pressures, in particular in relation to drug treatment, certainly also has an important role to play here in the persistence of these biological hotspots, together with intensive transmission and rapid re-infection of the hosts. It is thus important to implement a One-health framework in further control programs where humans at the community level (e.g., both children and adults), but also the parasites remaining in the (relatively) "drug free" environment (e.g., in snails, and in animals), would be targeted for reduction in schistosomiasis. The current lack of specific genetic markers for PZQ resistance and virulence, but also the fact that we mostly rely on neutral markers is a crux limitation in our ability to understand the role of parasite genetic variation in host disease phenotype in human schistosomiasis, including the wide-scale effect of drug treatment on parasite population genetic response. Thus, the development of more powerful non-neutral molecular markers (i.e., SNPs) at a genome wide level is warranted if we are willing to assess the strength of the genetic bottleneck after treatment, dissect re-infection from persistent infections, but also genetic changes that may be associated with the parasite's fecundity, virulence and associated host induced morbidity.

Once SNPs are identified, elucidating their role thus confirming them as markers of virulence within the parasite population will only be possible if, at the same time, we obtain a greater understanding of the dysregulated immune response that leads to the development of liver PPF and severe bladder, upper urinary tract and genital tract fibrosis in humans. This includes the dissection of the similarities and differences observed in the immuno-pathology seen in S. mansoni and S. haematobium infections, as virulence factors may differ between the two species and indeed within species across their geographical range. Of note, the newly released WHO NTD Roadmap 2021 to 2030 (19), explicitly highlights the need for defined indicators of host morbidity. Without this linkage between parasite factors and host response, our certainty that we are monitoring for parasite SNPs that are indicative of potential resurgent hotspots of morbidity if the environmental factors are not controlled will be impacted.

\section{CASE STUDY: UGANDAN ALBERTINE REGION AND THE FIBROSCHOT PROJECT}

Working with the Schistosomiasis Control Initiative, Uganda was at the forefront of establishment of the MDA-based control programmes within SSA with the first communities there being treated in 2003. These communities were based upon the shores of Lake Albert, an area that had historically been shown to have high infection intensities and a high prevalence of severe schistosomiasis $(78,172,283)$. Success of the annual PC approach was established both empirically through measurements (172) and via anthropological investigations (284). However, in recent years reports of a high incidence of individuals presenting with portal hypertension at health clinics has indicated that severe schistosomiasis is currently prevalent within these areas (285). Given the age-association and longterm exposure that can lead to PPF, one explanation is that those presenting at the clinics with PPF are individuals who were not treated as children. However, high reported programme coverage rates from the districts indicate that the situation on Lake Albert is representative of a biological hotspot, where local factors in the ecology and host behavior of transmission have resulted in poor control of infection. Biological hotspots also occur in Ugandan communities resident in the fishing villages of Lake Victoria, with equally poor resolution of infection prevalence through the control programme (17). However, while those living on the shores of Lake Albert harbor high prevalence and strong intensities of infection with high rates of PPF $(33,35,77-79$, 283), in Lake Victoria communities, even prior to the implementation of the control programmes when infection levels were very high, observation of PPF was rare despite the infection levels of a comparable level to those in Lake Albert communities (36). These findings are indicative that not only is Lake Albert a biological hotspot of transmission, but that factors at the parasite-host interface lead to this being a morbidity hotspot. As PPF in children has been shown to generally be mild (277) and the observed association with infection intensities indicating that they are in an active phase of developing PPF there is some hope that the PPF observed can be reversed with PZQ treatment, but that the current annual administration is insufficient. From this the FibroScHot trial, which aims to determine whether treatment of schoolchildren twice or four times per year provides morbidity control was devised.

The primary objective of the trial at the center of the FibroScHot project is to compare the impact of twice and four times treatments annually with PZQ, relative to the standard once annual treatment, on the prevalence of $S$. mansoniassociated PPF of the liver. A secondary objective is to compare the effect of the same treatment strategies on the mean infection intensity of $S$. mansoni. In addition to the traditional statistical analysis of results, the consortium includes mathematical modelling expertise to allow impact of the strategies on a term longer than the 2-year duration of the trial to be examined. Predictive mathematical models will initially be built using historical data from the village of Booma for which behavioral aspects of human host exposure are well defined (286), though FibroScHot itself will be conducted in the neighboring district of Hoima. Data from the FibroScHot trial will be used to validate these models. Crucially, exploratory studies will run alongside the main clinical trial to determine any significant limitations to this solely PC approach to disease control. Medical anthropological analyses will examine the social and cultural influences on treatment uptake, while in 
context of this review both parasite and host factors will be studied. While we are cognizant of the potential role of coinfection, particularly viral hepatitis (B and C) and Plasmodium, in exacerbating morbidity within these communities, as the individual randomized trial design assumes co-infection will be comparable across the study arms, the study design is not optimal for research into this and it will not be explored further within FibroScHot.

The fact that PPF is more prevalent in Lake Albert region than the Lake Victoria region may be predicted to be due, at least in part, to parasite factors that prevent the successful downregulation of immuno-pathological responses, which over time could lead to expansive fibrosis. The FibroScHot study aims to make some progress on the above by integrating examination of the childhood responses to schistosome egg stimulation with examination of parasite population genetics and genome sequences. As discussed in the main article, due to the epidemiological patterns of PPF, many human studies that have investigated immuno-pathological mechanisms of PPF report results biased towards the responses observed amongst adults. Exploring the immune responses of children in the active phase of developing PPF could give us insight into the mechanisms that drive the development of severe schistosomiasis. The childhood PPF observed in Lake Albert region of Uganda gives us an opportunity to do this. While the project is not powered to provide clear evidence of "pathogenicity" related regions within the parasites, it will allow us to identify changes in parasite populations through time. Examining gene flow within the parasite population will identify specific isolates associated with reduced egg reduction rates or persistent morbidity. This population genetics approach will be combined with genome wide sequencing of selected parasite isolates, allowing us to elucidate both potential indicators of reduced PZQ efficacy and/or specific novel genotypes relating to increased PPF within these populations. This will constitute the initial steps required for fully integrated research into the interactions between parasite and host factors that may contribute to Lake Albert being a morbidity hotspot.

\section{CONCLUSIONS}

Schistosomiasis is a multifactorial disease in which several host and parasite factors including their interaction with the environment may act at each step of the parasite's life cycle $(287,288)$. While the reasons behind discrepancies in clinical outcome remain ambiguous and the relationship between

\section{REFERENCES}

1. Colley DG, Bustinduy AL, Secor WE, King CH. Human schistosomiasis. Lancet (London England) (2014) 383:2253-64. doi: 10.1016/S0140-6736(13)61949-2

2. Hotez PJ, Fenwick A, Savioli L, Molyneux DH. Rescuing the bottom billion through control of neglected tropical diseases. Lancet (2009) 373:1570-5. doi: 10.1016/S0140-6736(09)60233-6 infection intensity and organ-related morbidity is complex, cumulative evidence is now showing that as well as hostspecific factors shaping the genetic composition of schistosome populations $(156,190,191)$, parasite genetic differences may indeed be important in the development of human host morbidity $(53,133,175,176,289)$, and the characteristics of morbidity responses to them (150). Regardless of whether or not morbidity hotspots are driven by intrinsic host factors, parasite factors, or a combination of both in complex interplay with the environment, the fact that these hotspots exist does mean that the use of infection parameters to define morbidity control, and in the context of the new Roadmap, elimination of schistosomiasis as a public health problem in all 78 endemic countries by 2030 , is likely insufficient. Given particularly that severe morbidity in these hotspots may develop at lower infection levels, or in a greater proportion of individuals, if the host-parasite relationship allows, the current use of an infection parameter alone to define success could well be misleading, leaving a significant number of individuals in further need without appropriate treatment. There are of course financial and logistical problems to overcome if morbidity screenings, in the absence of easily measurable markers of morbidity, were to become routine in control programmes, not least the requirement for the skilled personnel to conduct the ultrasonographic investigations. One approach would be for morbidity screens to be integrated into the verification of elimination as a public health problem within countries. Ultimately, understanding how the morbidity profiles of schistosomiasis differ and change across different endemic areas will prove to be of ever-increasing critical importance to the monitoring and evaluation of control programs in reaching the goal of elimination of schistosomiasis as a public health problem in all endemic countries.

\section{AUTHOR CONTRIBUTIONS}

PM and JK-S wrote the first draft of the article, with subsequent input from EMT, SW and JW. All authors contributed to the article and approved the submitted version.

\section{FUNDING}

All authors were supported through the FibroScHot project which is part of the EDCTP2 programme supported by the European Union (RIA2017NIM-1842-FibroScHot).

3. King CH. Parasites and poverty: The case of schistosomiasis. Acta Trop (2010) 113:95-104. doi: 10.1016/j.actatropica.2009.11.012

4. Kolářová L, Horák P, Skírnisson K, Marečková H, Doenhoff M. Cercarial dermatitis, a neglected allergic disease. Clin Rev Allergy Immunol (2013) 45:63-74. doi: 10.1007/s12016-012-8334-y

5. Hoeffler DF. Cercarial Dermatitis. Arch Environ Health Int J (1974) 29:225-9. doi: $10.1080 / 00039896.1974 .10666573$ 
6. Doherty JF, Moody AH, Wright SG. Katayama fever: An acute manifestation of schistosomiasis. BMJ (1996) 313:1071-2. doi: 10.1136/ bmj.313.7064.1071

7. Jourdane J, Imbert-Establet D, Tchuenté LAT. Parthenogenesis in Schistosomatidae. Parasitol Today (1995) 11:427-30. doi: 10.1016/01694758(95)80029-8

8. Doenhoff MJ. A role for granulomatous inflammation in the transmission of infectious disease schistosomiasis and tuberculosis. Parasitology (1997) 115:113-25. doi: 10.1017/S0031182097001972

9. King $\mathrm{CH}$, Dangerfield-Cha M. The unacknowledged impact of chronic schistosomiasis. Chronic Illn (2008) 4:65-79. doi: 10.1177/ 1742395307084407

10. Ezeamama AE, Bustinduy AL, Nkwata AK, Martinez L, Pabalan N, Boivin MJ, et al. Cognitive deficits and educational loss in children with schistosome infection-A systematic review and meta-analysis. PloS Negl Trop Dis (2018) 12:1-23. doi: 10.1371/journal.pntd.0005524

11. Gryseels B, Polman K, Clerinx J, Kestens L, Doumenge J, Mott K, et al. Human schistosomiasis. Lancet (London England) (2006) 368:1106-18. doi: 10.1016/S0140-6736(06)69440-3

12. Kjetland EF, Leutscher PDC, Ndhlovu PD. A review of female genital schistosomiasis. Trends Parasitol (2016) 28:58-65. doi: 10.1016/ j.pt.2011.10.008

13. Feldmeier H, Krantz I, Poggensee G. Female Genital Schistosomiasis as a Risk-Factor for the Transmission of HIV. Int J STD AIDS (1994) 5:368-72. doi: 10.1177/095646249400500517

14. Cheever AW, Andrade ZA. Pathological lesions associated with Schistosoma mansoni infection in man. Trans R Soc Trop Med Hyg (1967) 61:626-39. doi: 10.1016/0035-9203(67)90125-3

15. Cheever AW. A quantitative post-mortem study of Schistosomiasis mansoni in man. Am J Trop Med Hyg (1968) 17:38-64. doi: 10.4269/ajtmh.1968.17.38

16. Webster JP, Molyneux DH, Hotez PJ, Fenwick A. The contribution of mass drug administration to global health: Past, present and future. Philos Trans $R$ Soc B Biol Sci (2014) 369:20130434. doi: 10.1098/rstb.2013.0434

17. Deol AK, Fleming FM, Calvo-Urbano B, Walker M, Bucumi V, Gnandou I, et al. Schistosomiasis - Assessing progress toward the 2020 and 2025 global goals. N Engl J Med (2019) 381:2519-28. doi: 10.1056/NEJMoa1812165

18. World Health Organization. Accelerating Work to Overcome the Global Impact of Neglected Tropical Diseases: A Roadmap for Implementation. Geneva, Switzerland, 2012: World Health Organization WHO (2012). Available at: http://whqlibdoc.who.int/hq/2012/WHO_HTM_NTD_2012. 1_eng.pdf?ua=1.

19. World Health Organization. Ending the neglect to attain the sustainable development goals: a road map for neglected tropical diseases 2021-2030. Geneva, Switzerland: World Health Organization (WHO) (2021). Available at: https://www.who.int/neglected_diseases/Ending-the-neglect-to-attainthe-SDGs-NTD-Roadmap.pdf.

20. Jing X, Shi-Zhu L, Jia-Xu C, Li-Yong W, Xiao-Nong Z. [Playing the guiding roles of national criteria and precisely eliminating schistosomiasis in P. R. China]. Zhongguo Xue Xi Chong Bing Fang Zhi Za Zhi (2017) 29:1-4. doi: 10.16250/j.32.1374.2017012

21. Colley DG, Andros TS, Campbell CH. Schistosomiasis is more prevalent than previously thought: What does it mean for public health goals, policies, strategies, guidelines and intervention programs? Infect Dis Poverty (2017) 6:4-11. doi: 10.1186/s40249-017-0275-5

22. Crellen T, Walker M, Lamberton PHL, Kabatereine NB, Tukahebwa EM, Cotton JA, et al. Reduced Efficacy of Praziquantel Against Schistosoma mansoni Is Associated with Multiple Rounds of Mass Drug Administration. Clin Infect Dis (2016) 63:1151-9. doi: 10.1093/cid/ciw506

23. Levecke B, Vlaminck J, Andriamaro L, Ame S, Belizario V, Degarege A, et al. Evaluation of the therapeutic efficacy of praziquantel against schistosomes in seven countries with ongoing large-scale deworming programs. Int $J$ Parasitol Drugs Drug Resist (2020) 14:183-7. doi: 10.1016/j.ijpddr.2020. 10.003

24. Liang S, Yang C, Zhong B, Qiu D. Re-emerging schistosomiasis in hilly and mountainous areas of Sichuan, China. Bull World Health Organ (2006) 84:139-44. doi: 10.2471/BLT.05.025031

25. Kittur N, Binder S, Campbell CH, King CH, Kinung'Hi S, Olsen A, et al. Defining persistent hotspots: Areas that fail to decrease meaningfully in prevalence after multiple years of mass drug administration with praziquantel for control of schistosomiasis. Am J Trop Med Hyg (2017) 97:1810-7. doi: 10.4269/ajtmh.17-0368

26. Wiegand RE, Mwinzi PNM, Montgomery SP, Chan YYL, Andiego K, Omedo $\mathrm{M}$, et al. A persistent hotspot of schistosoma mansoni infection in a five-year randomized trial of praziquantel preventative chemotherapy strategies. J Infect Dis (2017) 216:1425-33. doi: 10.1093/infdis/jix496

27. Pennance T, Person B, Muhsin MA, Khamis AN, Muhsin J, Khamis IS, et al. Urogenital schistosomiasis transmission on Unguja Island, Zanzibar: Characterisation of persistent hot-spots. Parasit Vectors (2016) 9:1-13. doi: 10.1186/s13071-016-1847-0

28. Webster JP, Neves MI, Webster BL, Pennance T, Rabone M, Gouvras AN, et al. Parasite Population Genetic Contributions to the Schistosomiasis Consortium for Operational Research and Evaluation within Sub-Saharan Africa. Am J Trop Med Hyg (2020) 103:1-12. doi: 10.4269/ajtmh.19-0827

29. King CH, Kittur N, Binder S, Campbell CH, N'Goran EK, Meite A, et al. Impact of Different Mass Drug Administration Strategies for Gaining and Sustaining Control of Schistosoma mansoni and Schistosoma haematobium Infection in Africa. Am J Trop Med Hyg (2020) 103(1_Suppl):14-23. doi: 10.4269/ajtmh.19-0829

30. Ezeamama AE, He C, Shen Y, Yin XP, Binder SC, Campbell CH, et al. Gaining and sustaining schistosomiasis control: Study protocol and baseline data prior to different treatment strategies in five African countries. BMC Infect Dis (2016) 16:1-11. doi: 10.1186/s12879-016-1575-2

31. Allan F, Ame SM, Tian-Bi Y-NT, Hofkin BV, Webster BL, Diakité NR, et al. Snail-Related Contributions from the Schistosomiasis Consortium for Operational Research and Evaluation Program Including Xenomonitoring, Focal Mollusciciding, Biological Control, and Modeling. Am J Trop Med Hyg (2020) 103:1-14. doi: 10.4269/ajtmh.19-0831

32. Kittur N, King CH, Campbell CH, Kinung'hi S, Mwinzi PNM, Karanja DMS, et al. Persistent hotspots in schistosomiasis consortium for operational research and evaluation studies for gaining and sustaining control of schistosomiasis after four years of mass drug administration of praziquantel. Am J Trop Med Hyg (2019) 101:617-27. doi: 10.4269/ ajtmh.19-0193

33. Booth M, Vennervald BJ, Kabatereine NB, Kazibwe F, Ouma JH, Kariuki $\mathrm{CH}$, et al. Hepatosplenic morbidity in two neighbouring communities in Uganda with high levels of Schistosoma mansoni infection but very different durations of residence. Trans R Soc Trop Med Hyg (2004) 98:125-36. doi: 10.1016/s0035-9203(03)00018-x

34. Odongo-Aginya EI, Grigull L, Schweigmann U, Loroni-Lakwo T, Enrich $\mathrm{JHH}$, Gryseels B, et al. High prevalence and morbidity of Schistosoma mansoni along the Albert Nile in Uganda. Afr Health Sci (2002) 2:99-106.

35. Kabatereine NB, Kemijumbi J, Ouma JH, Kariuki HC, Richter J, Kadzo H et al. Epidemiology and morbidity of Schistosoma mansoni infection in a fishing community along Lake Albert in Uganda. Trans $R$ Soc Trop Med Hyg (2004) 98:711-8. doi: 10.1016/j.trstmh.2004.06.003

36. Tukahebwa EM, Magnussen P, Madsen H, Kabatereine NB, Nuwaha F, Wilson S, et al. A Very High Infection Intensity of Schistosoma mansoni in a Ugandan Lake Victoria Fishing Community Is Required for Association with Highly Prevalent Organ Related Morbidity. PloS Negl Trop Dis (2013) 7: e2268. doi: 10.1371/journal.pntd.0002268

37. Kabatereine NB, Brooker S, Koukounari A, Kazibwe F, Tukahebwa EM, Fleming FM, et al. Impact of a national helminth control programme on infection and morbidity in Ugandan schoolchildren. Bull World Health Organ (2007) 85:91-9. doi: 10.2471/BLT.06.030353

38. Mari L, Ciddio M, Casagrandi R, Perez-Saez J, Bertuzzo E, Rinaldo A, et al. Heterogeneity in schistosomiasis transmission dynamics. J Theor Biol (2017) 432:87-99. doi: 10.1016/j.jtbi.2017.08.015

39. Meurs L, Mbow M, Boon N, van den Broeck F, Vereecken K, Dièye TN, et al. Micro-Geographical Heterogeneity in Schistosoma mansoni and S. haematobium Infection and Morbidity in a Co-Endemic Community in Northern Senegal. PloS Negl Trop Dis (2013) 7:e2608. doi: 10.1371/ journal.pntd.0002608

40. Richards FO, Eigege A, Miri ES, Jinadu MY, Hopkins DR. Integration of mass drug administration programmes in Nigeria: The challenge of schistosomiasis. Bull World Health Organ (2006) 84:760. doi: 10.2471/ BLT.06.029652 
41. Aemero M, Boissier J, Climent D, Moné H, Mouahid G, Berhe N, et al. Genetic diversity, multiplicity of infection and population structure of Schistosoma mansoni isolates from human hosts in Ethiopia. BMC Genet (2015) 16:137. doi: 10.1186/s12863-015-0297-6

42. Gryseels B. Morbidity due to infection with Schistosoma mansoni: An update. Trop Geogr Med (1992) 44:189-200.

43. Doehring-Schwerdtfeger E, Kardorff R. Ultrasonography in schistosomiasis in Africa. Mem Inst Oswaldo Cruz (1995) 90:141-5. doi: 10.1590/S007402761995000200003

44. Tanabe M, Gonçalves J, Gonçalves FJ, Tateno S, Takeuchi T. Occurrence of a community with high morbidity associated with Schistosoma mansoni infection regardless of low infection intensity in north-east Brazil. Trans $R$ Soc Trop Med Hyg (1997) 91:144-9. doi: 10.1016/S0035-9203(97)90201-7

45. Boisier P, Ramarokoto CE, Ravoniarimbinina P, Rabarijaona L, Ravaoalimalala VE. Geographic differences in hepatosplenic complications of schistosomiasis mansoni and explanatory factors of morbidity. Trop Med Int Health (2001) 6:699-706. doi: 10.1046/j.1365-3156.2001.00781.x

46. Pugh RN, Bell DR, Gilles HM. Malumfashi Endemic Diseases Research Project, XV. The potential medical importance of bilharzia in northern Nigeria: a suggested rapid, cheap and effective solution for control of Schistosoma haematobium infection. Ann Trop Med Parasitol (1980) 74:597-613. doi: 10.1080/00034983.1980.11687393

47. Elem B, Vandal MT. Bilharziasis of the urinary tract in Zambia.(Observation on 100 consecutive cases). Med J Zambia (1981) 15:48-51.

48. Brouwer KC, Ndhlovu PD, Wagatsuma Y, Munatsi A, Shiff CJ. Epidemiological assessment of Schistosoma haematobium-induced kidney and bladder pathology in rural Zimbabwe. Acta Trop (2003) 85:339-47. doi: 10.1016/S0001-706X(02)00262-0

49. Mazigo HD, Dunne DW, Morona D, Lutufyo TE, Kinung'Hi SM, Kaatano G, et al. Periportal fibrosis, liver and spleen sizes among S. mansoni mono or co-infected individuals with human immunodeficiency virus-1 in fishing villages along Lake Victoria shores, North-Western, Tanzania. Parasit Vectors (2015) 8:1-13. doi: 10.1186/s13071-015-0876-4

50. Booth M, Vennervald BJ, Kenty LC, Butterworth AE, Kariuki HC, Kadzo H, et al. Micro-geographical variation in exposure to Schistosoma mansoni and malaria, and exacerbation of splenomegaly in Kenyan school-aged children. BMC Infect Dis (2004) 4:1-11. doi: 10.1186/1471-2334-4-13

51. Handzel T, Karanja DMS, Addiss DG, Hightower AW, Rosen DH, Colley DG, et al. Geographic distribution of schistosomiasis and soil-transmitted helminths in Western Kenya: implications for anthelminthic mass treatment. Am J Trop Med Hyg (2003) 69:318-23. doi: 10.4269/ ajtmh.2003.69.318

52. Guyatt H, Gryseels B, Smith T, Tanner M. Assessing the public health importance of Schistosoma mansoni in different endemic areas: attributable fraction estimates as an approach. Am J Trop Med Hyg (1995) 53:660-667. doi: 10.4269/ajtmh.1995.53.660

53. Mohamed-Ali Q, Elwali NMA, Abdelhameed AA, Mergani A, Rahoud S, Elagib KE, et al. Susceptibility to Periportal (Symmers) Fibrosis in Human Schistosoma mansoni Infections: Evidence That Intensity and Duration of Infection, Gender, and Inherited Factors Are Critical in Disease Progression. J Infect Dis (1999) 180:1298-306. doi: 10.1086/314999

54. Blanton RE, Abdel Salam E, Curtis Kariuki H, Magak P, Silva LK, Muchiri EM, et al. Population-based differences in Schistosoma mansoni- and hepatitis C-induced disease. J Infect Dis (2002) 185:1644-9. doi: 10.1086/ 340574

55. Butterworth AE, Dunne DW, Fulford AJ, Ouma JH, Sturrock RF. Immunity and morbidity in Schistosoma mansoni infection: quantitative aspects. Am J Trop Med Hyg (1996) 55:109-15. doi: 10.4269/ajtmh.1996.55.109

56. Secor WE, del Corral H, dos Reis MG, Ramos EA, Zimon AE, Matos EP, et al. Association of hepatosplenic schistosomiasis with HLA-DQB1 ${ }^{\star} 0201$. J Infect Dis (1996) 174:1131-5. doi: 10.1093/infdis/174.5.1131

57. Dessein AJ, Hillaire D, Elwali NEMA, Marquet S, Mohamed-Ali Q, Mirghani A, et al. Severe hepatic fibrosis in Schistosoma mansoni infection is controlled by a major locus that is closely linked to the interferon- $\gamma$ receptor gene. Am J Hum Genet (1999) 65:709-21. doi: $10.1086 / 302526$

58. Andrade G, Bertsch DJ, Gazzinelli A, King CH. Decline in infection-related morbidities following drug-mediated reductions in the intensity of
Schistosoma infection: A systematic review and meta-analysis. PLoS Neg Trop Dis (2017) 17:1-23. doi: 10.1371/journal.pntd.0005372

59. Webster JP, Gower CM, Norton AJ. Evolutionary concepts in predicting and evaluating the impact of mass chemotherapy schistosomiasis control programmes on parasites and their hosts. Evol Appl (2008) 1:66-83. doi: 10.1111/j.1752-4571.2007.00012.x

60. Fallon PG, Doenhoff MJ. Drug-resistant schistosomiasis: resistance to praziquantel and oxamniquine induced in Schistosoma mansoni in mice is drug specific. Am J Trop Med Hyg (1994) 51:83-8. doi: 10.4269/ ajtmh.1994.51.83

61. Coles GC, Bruce JI. In vitro selection of drug resistant Schistosoma mansoni. Int J Parasitol (1987) 17:767-71. doi: 10.1016/0020-7519(87)90057-9

62. William S, Sabra A, Ramzy F, Mousa M, Demerdash Z, Bennett JL, et al. Stability and reproductive fitness of Schistosoma mansoni isolates with decreased sensitivity to praziquantel. Int J Parasitol (2001) 31:1093-100. doi: 10.1016/S0020-7519(01)00215-6

63. Feng Z, Curtis J, Minchella DJ. The influence of drug treatment on the maintenance of schistosome genetic diversity. J Math Biol (2001) 43:52-68. doi: $10.1007 / \mathrm{s} 002850100092$

64. Cioli D, Botros SS, Wheatcroft-Francklow K, Mbaye A, Southgate V, Tchuenté LAT, et al. Determination of ED50 values for praziquantel in praziquantel-resistant and -susceptible Schistosoma mansoni isolates. Int J Parasitol (2004) 34:979-87. doi: 10.1016/j.ijpara.2004.05.001

65. Coeli R, Baba EH, Araujo N, Coelho PMZ, Oliveira G. Praziquantel Treatment Decreases Schistosoma mansoni Genetic Diversity in Experimental Infections. PloS Negl Trop Dis (2013) 7:3-8. doi: 10.1371/ journal.pntd.0002596

66. Davies CM, Webster JP, Woolhouse MEJ. Trade-offs in the evolution of virulence in an indirectly transmitted macroparasite. Proc R Soc B Biol Sci (2001) 268:251-7. doi: 10.1098/rspb.2000.1367

67. Webster JP, Davies CM. Coevolution and compatibility in the snailschistosome system. Parasitology (2001) 123(Suppl):S41-56. doi: 10.1017/ s0031182001008071

68. Davies CM, Fairbrother E, Webster JP. Mixed strain schistosome infections of snails and the evolution of parasite virulence. Parasitology (2002) 124:318. doi: 10.1017/s0031182001008873

69. Webster JP. Compatibility and sex in a snail-schistosome system. Parasitology (2001) 122:423-32. doi: 10.1017/s0031182001007442

70. Webster JP, Hoffman JI, Berdoy M. Parasite infection, host resistance and mate choice: Battle of the genders in a simultaneous hermaphrodite. Proc $R$ Soc B Biol Sci (2003) 270:1481-5. doi: 10.1098/rspb.2003.2354

71. Webster JP, Gower CM, Blair L. Do hosts and parasites coevolve? Empirical support from the Schistosoma system. Am Nat (2004) 164(Suppl):S33-51. doi: $10.1086 / 424607$

72. Webster JP, Shrivastava J, Johnson PJ, Blair L. Is host-schistosome coevolution going anywhere? BMC Evol Biol (2007) 7:1-11. doi: 10.1186/ 1471-2148-7-91

73. Gower CM, Webster JP. Fitness of indirectly transmitted pathogens: restraint and constraint. Evolution (2004) 58:1178-84. doi: 10.1111/j.00143820.2004.tb01698.x

74. Gower CM, Webster JP. Intraspecific competition and the evolution of virulence in a parasitic trematode. Evolution (2005) 59:544-53. doi: 10.1111/ j.0014-3820.2005.tb01014.x

75. Elmorshedy H, Bergquist R, El-Ela NEA, Eassa SM, Elsakka EE, Barakat R. Can human schistosomiasis mansoni control be sustained in high-risk transmission foci in Egypt? Parasit Vectors (2015) 8:1-8. doi: 10.1186/ s13071-015-0983-2

76. Assaré RK, Tian-Bi YNT, Yao PK, N'Guessan NA, Ouattara M, Yapi A, et al. Sustaining Control of Schistosomiasis Mansoni in Western Côte d'Ivoire: Results from a SCORE Study, One Year after Initial Praziquantel Administration. PloS Negl Trop Dis (2016) 10:1-17. doi: 10.1371/ journal.pntd.0004329

77. Zhang Y, Koukounari A, Kabatereine N, Fleming F, Kazibwe F, Tukahebwa $\mathrm{E}$, et al. Parasitological impact of 2-year preventive chemotherapy on schistosomiasis and soil-transmitted helminthiasis in Uganda. BMC Med (2007) 5:1-11. doi: 10.1186/1741-7015-5-27

78. Ongom VL, Bradley DJ. The epidemiology and consequences of Schistosoma mansoni infection in West Nile, Uganda. IField studies of a community at 
Panyagoro. Trans R Soc Trop Med Hyg (1972) 66:835-51. doi: 10.1016/00359203(72)90118-6

79. Frenzel K, Grigull L, Odongo-Aginya E, Ndugwa CM, Loroni-Lakwo T, Schweigmann U, et al. Evidence for a long-term effect of a single dose of praziquantel on Schistosoma mansoni-induced hepatosplenic lesions in northern Uganda. Am J Trop Med Hyg (1999) 60:927-31. doi: 10.4269/ ajtmh.1999.60.927

80. Lessler J, Azman AS, McKay HS, Moore SM. What is a Hotspot Anyway? Am J Trop Med Hyg (2017) 96:1270-3. doi: 10.4269/ajtmh.16-0427

81. Wijngaarden PJ, Van Den Bosch F, Jeger MJ, Hoekstra RF. Adaptation to the cost of resistance: A model of compensation, recombination, and selection in a haploid organism. Proc R Soc B Biol Sci (2005) 272:85-9. doi: 10.1098/ rspb.2004.2910

82. Andersson DI, Hughes D. Antibiotic resistance and its cost: is it possible to reverse resistance? Nat Rev Microbiol (2010) 8:260-71. doi: 10.1038/ nrmicro2319

83. Leathwick DM. Managing anthelmintic resistance-Parasite fitness, drug use strategy and the potential for reversion towards susceptibility. Vet Parasitol (2013) 198:145-53. doi: 10.1016/j.vetpar.2013.08.022

84. Viana M, Faust CL, Haydon DT, Webster JP, Lamberton PHL. The effects of subcurative praziquantel treatment on life-history traits and trade-offs in drug-resistant Schistosoma mansoni. Evol Appl (2018) 11:488-500. doi: $10.1111 /$ eva. 12558

85. Zwang J, Olliaro PL. Clinical Efficacy and Tolerability of Praziquantel for Intestinal and Urinary Schistosomiasis-A Meta-analysis of Comparative and Non-comparative Clinical Trials. PloS Negl Trop Dis (2014) 8:e3286. doi: 10.1371/journal.pntd.0003286

86. Melman SD, Steinauer ML, Cunningham C, Kubatko LS, Mwangi IN, Wynn $\mathrm{NB}$, et al. Reduced susceptibility to praziquantel among naturally occurring Kenyan isolates of Schistosoma mansoni. PloS Negl Trop Dis (2009) 3:e504. doi: 10.1371/journal.pntd.0000504

87. Ismail M, Botros S, Metwally A, William S, Farghally A, Tao LF, et al. Resistance to praziquantel: direct evidence from Schistosoma mansoni isolated from Egyptian villagers. Am J Trop Med Hyg (1999) 60:932-5. doi: 10.4269/ajtmh.1999.60.932

88. Gryseels B, Mbaye A, De Vlas SJ, Stelma FF, Guissé F, Van Lieshout L, et al. Are poor responses to praziquantel for the treatment of Schistosoma mansoni infections in Senegal due to resistance? An overview of the evidence. Trop Med Int Health (2001) 6:864-73. doi: 10.1046/j.13653156.2001.00811.x

89. Huyse T, Van den Broeck F, Jombart T, Webster BL, Diaw O, Volckaert FAM, et al. Regular treatments of praziquantel do not impact on the genetic make-up of Schistosoma mansoni in Northern Senegal. Infect Genet Evol (2013) 18:100-5. doi: 10.1016/j.meegid.2013.05.007

90. Da Silva IM, Thiengo R, Conceição MJ, Rey L, Lenzi HL, Filho EP, et al. Therapeutic failure of praziquantel in the treatment of Schistosoma haematobium infection in Brazilians returning from Africa. Mem Inst Oswaldo Cruz (2005) 100:445-9. doi: 10.1590/s0074-02762005000400018

91. Kotze AC, Kopp SR. The potential impact of density dependent fecundity on the use of the faecal egg count reduction test for detecting drug resistance in human hookworms. PloS Negl Trop Dis (2008) 2:e297. doi: 10.1371/ journal.pntd.0000297

92. Anderson RM, Anderson B, May RM. Infectious diseases of humans: dynamics and control. Oxford, England: Oxford University Press (1992).

93. Anderson RM, May RM. Helminth infections of humans: mathematical models, population dynamics, and control. Adv Parasitol (1985) 24:1-101. doi: 10.1016/s0065-308x(08)60561-8

94. Hall A, Holland C. Geographical variation in Ascaris lumbricoides fecundity and its implications for helminth control. Parasitol Today (2000) 16:540-4. doi: 10.1016/S0169-4758(00)01779-8

95. Anderson RM, May RM. Age-related changes in the rate of disease transmission: Implications for the design of vaccination programmes. J Hyg (Lond) (1985) 94:365-436. doi: 10.1017/S002217240006160X

96. Anderson RM, May RM. Infectious diseases of humans: dynamics and control. In: Infect Dis Humans Dyn Control. Oxford, England: Oxford University Press (1991)

97. Cheever AW, Kamel IA, Elwi AM, Mosimann JE, Danner R. Schistosoma mansoni and S. haematobium infections in Egypt. II. Quantitative parasitological findings at necropsy. Am J Trop Med Hyg (1977) 26:70216. doi: $10.4269 /$ ajtmh.1977.26.702

98. Cheever AW. Density-dependent fecundity in Schistosoma mansoni infections in man: a reply. Trans R Soc Trop Med Hyg (1986) 80:991-2. doi: 10.1016/0035-9203(86)90284-1

99. Medley G, Anderson RM. Density-dependent fecundity in Schistosoma mansoni infections in man. Trans R Soc Trop Med Hyg (1985) 79:532-4. doi: 10.1016/0035-9203(85)90087-2

100. Wertheimer SP, Vermund SH, Lumey LH, Singer B. Lack of demonstrable density-dependent fecundity of schistosomiasis mansoni: analyses of Egyptian quantitative human autopsies. Am J Trop Med Hyg (1987) 37:79-84. doi: 10.4269/ajtmh.1987.37.79

101. Gryseels B, De Vlas SJ. Worm burdens in schistosome infections. Parasitol Today (1996) 12:115-9. doi: 10.1016/0169-4758(96)80671-5

102. Polman K, De Vlas SJ, Van Lieshout L, Deelder AM, Gryseels B. Evaluation of density-dependent fecundity in human Schistosoma mansoni infections by relating egg counts to circulating antigens through Deming regression. Parasitology (2001) 122:161-7. doi: 10.1017/S0031182001007193

103. Gower CM, Gabrielli AF, Sacko M, Dembelle R, Golan R, Emery AM, et al. Population genetics of Schistosoma haematobium: development of novel microsatellite markers and their application to schistosomiasis control in Mali. Parasitology (2011) 138:978-94. doi: 10.1017/S0031182011000722

104. Agnew A, Fulford AJ, Mwanje MT, Gachuhi K, Gutsmann V, Krijger FW, et al. Age-dependent reduction of schistosome fecundity in Schistosoma haematobium but not Schistosoma mansoni infections in humans. Am J Trop Med Hyg (1996) 55:338-43. doi: 10.4269/ajtmh.1996.55.338

105. Wilson S, Jones FM, van Dam GJ, Corstjens PLAM, Riveau G, Fitzsimmons $\mathrm{CM}$, et al. Human Schistosoma haematobium antifecundity immunity is dependent on transmission intensity and associated with immunoglobulin G1 to worm-derived antigens. J Infect Dis (2014) 210:2009-16. doi: 10.1093/ infdis/jiu374

106. Gower CM, Gehre F, Marques SR, Lamberton PHL, Lwambo NJ, Webster JP. Phenotypic and genotypic monitoring of Schistosoma mansoni in Tanzanian schoolchildren five years into a preventative chemotherapy national control programme. Parasit Vectors (2017) 10:1-12. doi: 10.1186/s13071-017-2533-6

107. Neves MI, Webster JP, Walker M. Estimating helminth burdens using sibship reconstruction. Parasit Vectors (2019) 12:1-12. doi: 10.1186/ s13071-019-3687-1

108. Buck JC, De Leo GA, Sokolow SH. Concomitant Immunity and Worm Senescence May Drive Schistosomiasis Epidemiological Patterns: An EcoEvolutionary Perspective. Front Immunol (2020) 11:160. doi: 10.3389/ fimmu.2020.00160

109. Pullan R, Brooker S. The health impact of polyparasitism in humans: Are we under-estimating the burden of parasitic diseases? Parasitology (2008) 135:783-94. doi: 10.1017/S0031182008000346

110. Griffiths EC, Pedersen AB, Fenton A, Petchey OL. The nature and consequences of coinfection in humans. J Infect (2011) 63:200-6. doi: 10.1016/j.jinf.2011.06.005

111. Cunin P, Tchuem Tchuenté LA, Poste B, Djibrilla K, Martin PMV. Interactions between Schistosoma haematobium and Schistosoma mansoni in humans in north Cameroon. Trop Med Int Health (2003) 8:1110-7. doi: 10.1046/j.1360-2276.2003.01139.x

112. Cunin P, Griffet A, Poste B, Djibrilla K, Martin PMV. Epidemic Schistosoma mansoni in a known S. haematobium area. Trans R Soc Trop Med Hyg (2000) 94:657-60. doi: 10.1016/S0035-9203(00)90221-9

113. Garba A, Labbo R, Tohon Z, Sidiki A, Djibrilla A. Emergence of Schistosoma mansoni in the Niger River valley, Niger. Trans R Soc Trop Med Hyg (2004) 98:296-8. doi: 10.1016/S0035-9203(03)00070-1

114. Huyse T, Van den Broeck F, Hellemans B, Volckaert FAM, Polman K. Hybridisation between the two major African schistosome species of humans. Int J Parasitol (2013) 43:687-9. doi: 10.1016/j.ijpara.2013.04.001

115. Knowles SCL, Webster BL, Garba A, Sacko M, Diaw OT, Fenwick A, et al. Epidemiological Interactions between Urogenital and Intestinal Human Schistosomiasis in the Context of Praziquantel Treatment across Three West African Countries. PloS Negl Trop Dis (2015) 9:1-25. doi: 10.1371/ journal.pntd.0004019

116. Gouvras AN, Kariuki C, Koukounari A, Norton AJ, Lange CN, Ireri E, et al. The impact of single versus mixed Schistosoma haematobium and $S$. 
mansoni infections on morbidity profiles amongst school-children in Taveta, Kenya. Acta Trop (2013) 128:309-17. doi: 10.1016/j.actatropica.2013.01.001

117. Koukounari A, Fenwick A, Whawell S, Kabatereine NB, Kazibwe F, Tukahebwa EM, et al. Morbidity indicators of Schistosoma mansoni: Relationship between infection and anemia in Ugandan schoolchildren before and after praziquantel and albendazole chemotherapy. Am J Trop Med Hyg (2006) 75:278-86. doi: 10.4269/ajtmh.2006.75.278

118. Huyse T, Boon NAM, Van den Broeck F, Mbow M, Chaturvedi A, Meurs L, et al. Evolutionary epidemiology of schistosomiasis: linking parasite genetics with disease phenotype in humans. Int J Parasitol (2018) 48:107-15. doi: 10.1016/j.ijpara.2017.07.010

119. Ernould JC, Ba K, Sellin B. Increase of intestinal schistosomiasis after praziquantel treatment in a Schistosoma haematobium and Schistosoma mansoni mixed focus. Acta Trop (1999) 73:143-52. doi: 10.1016/S0001-706X (99)00013-3

120. Huyse T, Webster BL, Geldof S, Stothard JR, Diaw OT, Polman K, et al. Bidirectional introgressive hybridization between a cattle and human schistosome species. PloS Pathog (2009) 5:e1000571. doi: 10.1371/ journal.ppat.1000571

121. Meurs L, Mbow M, Vereecken K, Menten J, Mboup S, Polman K. Bladder Morbidity and Hepatic Fibrosis in Mixed Schistosoma haematobium and S. mansoni Infections: A Population-Wide Study in Northern Senegal. PloS Negl Trop Dis (2012) 6:1-8. doi: 10.1371/journal.pntd.0001829

122. Léger E, Garba A, Hamidou AA, Webster BL, Pennance T, Rollinson D, et al. Introgressed Animal Schistosomes Schistosoma curassoni and S. bovis. Emerg Infect Dis (2016) 22:2212-5. doi: 10.3201/eid2212.160644

123. Léger E, Borlase A, Fall CB, Diouf ND, Diop SD, Yasenev L, et al. Prevalence and distribution of schistosomiasis in human, livestock, and snail populations in northern Senegal: a One Health epidemiological study of a multi-host system. Lancet Planet Health (2020) 4:e330-42. doi: 10.1016/ S2542-5196(20)30129-7

124. Leger E, Webster JP. Hybridizations within the Genus Schistosoma: Implications for evolution, epidemiology and control. Parasitology (2017) 144:65-80. doi: 10.1017/S0031182016001190

125. Webster BL, Diaw OT, Seye MM, Webster JP, Rollinson D. Introgressive Hybridization of Schistosoma haematobium Group Species in Senegal: Species Barrier Break Down between Ruminant and Human Schistosomes. PloS Negl Trop Dis (2013) 7:e2110. doi: 10.1371/journal.pntd.0002110

126. Moné $\mathrm{H}$, Holtfreter MC, Allienne JF, Mintsa-Nguéma R, Ibikounlé $M$, Boissier J, et al. Introgressive hybridizations of Schistosoma haematobium by Schistosoma bovis at the origin of the first case report of schistosomiasis in Corsica (France, Europe). Parasitol Res (2015) 114:4127-33. doi: 10.1007/ s00436-015-4643-4

127. Boissier J, Grech-Angelini S, Webster BL, Allienne J-F, Huyse T, Mas-Coma $\mathrm{S}$, et al. Outbreak of urogenital schistosomiasis in Corsica (France): an epidemiological case study. Lancet Infect Dis (2016) 16:971-9. doi: 10.1016/ S1473-3099(16)00175-4

128. Webster JP, Gower CM, Knowles SCL, Molyneux DH, Fenton A. One health - an ecological and evolutionary framework for tackling Neglected Zoonotic Diseases. Evol Appl (2016) 9:313-33. doi: 10.1111/eva.12341

129. King KC, Stelkens RB, Webster JP, Smith DF, Brockhurst MA. Hybridization in Parasites: Consequences for Adaptive Evolution, Pathogenesis, and Public Health in a Changing World. PloS Pathog (2015) 11:1-12. doi: 10.1371/ journal.ppat.1005098

130. Detwiler JT, Criscione CD. An infectious topic in reticulate evolution: Introgression and hybridization in animal parasites. Genes (Basel) (2010) 1:102-23. doi: 10.3390/genes 1010102

131. Catalano S, Léger E, Fall CB, Borlase A, Diop SD, Berger D, et al. Multihost Transmission of Schistosoma mansoni in Senegal, 2015-2018. Emerg Infect Dis J (2020) 26:1234. doi: 10.3201/eid2606.200107

132. Afifi M, Jiman-Fatani A, Al-Hussainy N, Al-Rabia M, Bogari A. Genetic diversity among natural populations of Schistosoma haematobium might contribute to inconsistent virulence and diverse clinical outcomes. J Microsc Ultrastruct (2016) 4:222. doi: 10.1016/j.jmau.2016.04.002

133. Brouwer KC, Ndhlovu PD, Wagatsuma Y, Munatsi A, Shiff CJ. Urinary tract pathology attributed to Schistosoma haematobium: Does parasite genetics play a role? Am J Trop Med Hyg (2003) 68:456-62. doi: 10.4269/ ajtmh.2003.68.456
134. Morrison LJ, McLellan S, Sweeney L, Chan CN, MacLeod A, Tait A, et al. Role for parasite genetic diversity in differential host responses to Trypanosoma brucei infection. Infect Immun (2010) 78:1096-108. doi: 10.1128/IAI.00943-09

135. Barrett MP, Burchmore RJS, Stich A, Lazzari JO, Frasch AC, Cazzulo JJ, et al. The trypanosomiases. Lancet (London England) (2003) 362:1469-80. doi: 10.1016/S0140-6736(03)14694-6

136. Wilson K, Bjørnstad ON, Dobson AP, Merler S, Poglayen G, Randolf SE, et al. Heterogeneities in macroparasite infections: patterns and processes. In: Ecol Wildl Dis. Oxford, England: Oxford University Press (2001). 6-44.

137. Thiongo FW, Madsen H, Ouma JH, Andreassen J, Christensen NØ. Hostparasite relationships in infections with two Kenyan isolates of Schistosoma mansoni in NMRI mice. J Parasitol (1997) 83:330-2. doi: $10.2307 / 3284469$

138. Chunge RN, Karumba N, Ouma JH, Thiongo FW, Sturrock RF, Butterworth AE. Polyparasitism in two rural communities with endemic Schistosoma mansoni infection in Machakos District, Kenya. J Trop Med Hyg (1995) 98:440-4.

139. Sire C, Durand P, Pointier J-P, Théron A. Genetic diversity and recruitment pattern of Schistosoma mansoni in a Biomphalaria glabrata snail population: a field study using random-amplified polymorphic DNA markers. J Parasitol (1999) 85:436-41. doi: 10.2307/3285775

140. Imbert-Establet D, Combes C. Schistosoma mansoni: Comparison of a Caribbean and African strain and experimental crossing based on compatibility with intermediate hosts and Rattus rattus. Exp Parasitol (1986) 61:210-8. doi: 10.1016/0014-4894(86)90154-2

141. De Souza Dias LC, Deberaldini ER, De Jesus Pedro R. Use of praziquantel in patients with schistosomiasis mansoni previously treated with oxamniquine and/or hycanthone: Resistance of Schistosoma mansoni to schistosomicidal agents. Trans R Soc Trop Med Hyg (1982) 76:652-9. doi: 10.1016/0035-9203 (82) $90235-8$

142. Morrison DA. Systematics and the Origin of Species: On Ernst Mayr's 100th Anniversary. Syst Biol (2006) 55:357-9. doi: 10.1080/10635150500541565

143. Ross AGP, Bartley PB, Sleigh AC, Richard Olds G, Li Y, Williams GM, et al. Schistosomiasis. N Engl J Med (2002) 346:1212-20. doi: 10.1056/ NEJMra012396

144. Curtis J, Minchella DJ. Schistosome population genetic structure: when clumping worms is not just splitting hairs. Parasitol Today (2000) 16:68-71. doi: 10.1016/s0169-4758(99)01553-7

145. Nelson GS, Saoud MFA. A comparison of the pathogenicity of two geographical strains of Schistosoma mansoni in rhesus monkeys. J Helminthol (1968) 42:339-62. doi: 10.1017/S0022149X00017946

146. Kassim OO, Cheever AW, Richards CS. Schistosoma mansoni: Mice infected with different worm strains. Exp Parasitol (1979) 48:220-4. doi: 10.1016/ 0014-4894(79)90102-4

147. James C, Webbe G. A comparison of Sudanese and South African strains of Schistosoma haematobium. J Helminthol (1975) 49:191-7. doi: 10.1017/ S0022149X00023634

148. Le Clech W, Diaz R, Chevalier FD, McDew-White M, Anderson TJC. Striking differences in virulence, transmission and sporocyst growth dynamics between two schistosome populations. Parasit Vectors (2019) 12:1-12. doi: 10.1186/s13071-019-3741-z

149. Blair L, Webster JP, Barker GC. Isolation and characterization of polymorphic microsatellite markers in Schistosoma mansoni from Africa. Mol Ecol Notes (2001) 1:93-5. doi: 10.1046/j.1471-8278.2001.00042.x

150. Curtis J, Sorensen RE, Page LK, Minchella DJ. Microsatellite loci in the human blood fluke Schistosoma mansoni and their utility for other schistosome species. Mol Ecol Notes (2001) 1:143-5. doi: 10.1046/j.14718278.2001.00053.x

151. Durand P, Sire C, Théron A. Isolation of microsatellite markers in the digenetic trematode Schistosoma mansoni from Guadeloupe island. Mol Ecol (2000) 9:997-8. doi: 10.1046/j.1365-294X.2000.00939-4.x

152. Gower CM, Shrivastava J, Lamberton PHL, Rollinson D, Webster BL, Emery A, et al. Development and application of an ethically and epidemiologically advantageous assay for the multi-locus microsatellite analysis of Schistosoma mansoni. Parasitology (2007) 134:523-36. doi: 10.1017/S0031182006001685

153. Webster BL, Rabone M, Pennance T, Emery AM, Allan F, Gouvras A, et al. Development of novel multiplex microsatellite polymerase chain reactions to 
enable high-throughput population genetic studies of Schistosoma haematobium. Parasit Vectors (2015) 8:1-5. doi: 10.1186/s13071-015-1044-6

154. Steinauer ML, Hanelt B, Agola LE, Mkoji GM, Loker ES. Genetic structure of Schstosoma mansoni in western Kenya: the effects of geography and host sharing. Int J Parasitol (2009) 39:1353-62. doi: 10.1016/j.ijpara.2009.04.010

155. Morgan JAT, Dejong RJ, Adeoye GO, Ansa EDO, Barbosa CS, Bremond P, et al. Origin and diversification of the human parasite Schistosoma mansoni. Mol Ecol (2005) 14:3889-902. doi: 10.1111/j.1365-294X.2005.02709.x

156. Van Den Broeck F, Meurs L, Raeymaekers JAM, Boon N, Dieye TN, Volckaert FAM, et al. Inbreeding within human Schistosoma mansoni: Do host-specific factors shape the genetic composition of parasite populations? Heredity (Edinb) (2014) 113:32-41. doi: 10.1038/hdy.2014.13

157. Gower CM, Gouvras AN, Lamberton PHL, Deol A, Shrivastava J, Mutombo $\mathrm{PN}$, et al. Population genetic structure of Schistosoma mansoni and Schistosoma haematobium from across six sub-Saharan African countries: Implications for epidemiology, evolution and control. Acta Trop (2013) 128:261-74. doi: 10.1016/j.actatropica.2012.09.014

158. Curtis J, Sorensen RE, Minchella DJ. Schistosome genetic diversity: The implications of population structure as detected with microsatellite markers. Parasitology (2002) 125:51-9. doi: 10.1017/S0031182002002020

159. Lelo AE, Mburu DN, Magoma GN, Mungai BN, Kihara JH, Mwangi IN, et al. No Apparent Reduction in Schistosome Burden or Genetic Diversity Following Four Years of School-Based Mass Drug Administration in Mwea, Central Kenya, a Heavy Transmission Area. PloS Negl Trop Dis (2014) 8:e3221. doi: 10.1371/journal.pntd.0003221

160. van den Broeck F, Maes GE, Larmuseau MHD, Rollinson D, Sy I, Faye D, et al. Reconstructing colonization dynamics of the human parasite schistosoma mansoni following anthropogenic environmental changes in Northwest Senegal. PloS Negl Trop Dis (2015) 9:1-21. doi: 10.1371/journal.pntd.0003998

161. Dabo A, Durand P, Morand S, Diakite M, Langand J, Imbert-Establet D, et al. Distribution and genetic diversity of Schistosoma haematobium within its bulinid intermediate hosts in Mali. Acta Trop (1997) 66:15-26. doi: 10.1016/ S0001-706X(97)00670-0

162. Shiff C, Brouwer KC, Clow L. Schistosoma haematobium: Population Genetics of S . haematobium by Direct Measurement of Parasite Diversity Using RAPD - PCR. Exp Parasitol (2000) 51:47-51. doi: 10.1006/ expr.2000.4548

163. Thiele EA, Sorensen RE, Gazzinelli A, Minchella DJ. Genetic diversity and population structuring of Schistosoma mansoni in a Brazilian village. Int $J$ Parasitol (2008) 38:389-99. doi: 10.1016/j.ijpara.2007.07.011

164. Webster BL, Webster JP, Gouvras AN, Garba A, Lamine MS, Diaw OT, et al. DNA 'barcoding' of Schistosoma mansoni across sub-Saharan Africa supports substantial within locality diversity and geographical separation of genotypes. Acta Trop (2013) 128:250-60. doi: 10.1016/j.actatropica.2012.08.009

165. Steinauer ML, Blouin MS, Criscione CD. Applying evolutionary genetics to schistosome epidemiology. Infect Genet Evol (2010) 10:433-43. doi: 10.1016/ j.meegid.2010.02.007

166. Agola LE. Genetic diversity and population structure of Schistosoma mansoni within human infra-populations in Mwea, central Kenya assessed by microsatellite markers. J Invest Dermatol (2015) 135:612-5. doi: 10.1038/ jid.2014.371

167. Betson M, Sousa-Figueiredo JC, Kabatereine NB, Stothard JR. New Insights into the Molecular Epidemiology and Population Genetics of Schistosoma mansoni in Ugandan Pre-school Children and Mothers. PloS Negl Trop Dis (2013) 7:e2561. doi: 10.1371/journal.pntd.0002561

168. Barbosa LM, Reis EA, dos Santos CRA, Costa JM, Carmo TM, Aminu PT, et al. Repeated praziquantel treatments remodel the genetic and spatial landscape of schistosomiasis risk and transmission. Int J Parasitol (2016) 46:343-50. doi: 10.1016/j.ijpara.2016.01.007

169. Stothard JR, Webster BL, Weber T, Nyakaana S, Webster JP, Kazibwe F, et al. Molecular epidemiology of Schistosoma mansoni in Uganda: DNA barcoding reveals substantial genetic diversity within Lake Albert and Lake Victoria populations. Parasitology (2009) 136:1813-24. doi: 10.1017/S003118200999031X

170. Stothard JR, Sousa-Figueiredo JC, Betson M, Green HK, Seto EYW, Garba A, et al. Closing the praziquantel treatment gap: New steps in epidemiological monitoring and control of schistosomiasis in African infants and preschoolaged children. Parasitology (2011) 138:1593-606. doi: 10.1017/ S0031182011001235
171. Betson M, Sousa-Figueiredo JC, Rowell C, Kabatereine NB, Stothard JR. Intestinal schistosomiasis in mothers and young children in Uganda: Investigation of field-applicable markers of bowel morbidity. Am J Trop Med Hyg (2010) 83:1048-55. doi: 10.4269/ajtmh.2010.10-0307

172. Balen J, Stothard JR, Kabatereine NB, Tukahebwa EM, Kazibwe F, Whawell S, et al. Morbidity due to Schistosoma mansoni: an epidemiological assessment of distended abdomen syndrome in Ugandan school children with observations before and 1-year after anthelminthic chemotherapy. Trans R Soc Trop Med Hyg (2006) 100:1039-48. doi: 10.1016/j.trstmh. 2005.12.013

173. Standley CJ, Kabatereine NB, Lange CN, Lwambo NJS, Stothard JR. Molecular epidemiology and phylogeography of Schistosoma mansoni around Lake Victoria. Parasitology (2010) 137:1937-49. doi: 10.1017/ S0031182010000788

174. Faust CL, Crotti M, Moses A, Oguttu D, Wamboko A, Adriko M, et al. Twoyear longitudinal survey reveals high genetic diversity of Schistosoma mansoni with adult worms surviving praziquantel treatment at the start of mass drug administration in Uganda. Parasit Vectors (2019) 12:1-12. doi: 10.1186/s13071-019-3860-6

175. Saoud MF. The infectivity and pathogenicity of geographical strains of Schistosoma mansoni. Trans R Soc Trop Med Hyg (1966) 60:585-600. doi: 10.1016/0035-9203(66)90004-6

176. Yazdanpanah Y, Thomas AK, Kardorff R, Talla I, Sow S, Niang M, et al. Organometric investigations of the spleen and liver by ultrasound in Schistosoma mansoni endemic and nonendemic villages in Senegal. Am J Trop Med Hyg (1997) 57:245-9. doi: 10.4269/ajtmh. 1997.57.245

177. Nmorsi OPG, Ukwandu NCD, Ogoinja S, Blackie HOT, Odike MAC. Urinary tract pathology in Schistosoma haematobium infected rural Nigerians. Southeast Asian J Trop Med Public Health (2007) 38:32.

178. Gasmelseed N, Karamino NE, Abdelwahed MO, Hamdoun AO, Elmadani AE. Genetic diversity of Schistosoma haematobium parasite IS NOT associated with severity of disease in an endemic area in Sudan. BMC Infect Dis (2014) 14:1-8. doi: 10.1186/1471-2334-14-469

179. Barbosa LM, Silva LK, Reis EA, Azevedo TM, Costa JM, Blank WA, et al. Characteristics of the Human Host Have Little Influence on Which Local Schistosoma mansoni Populations Are Acquired. PloS Negl Trop Dis (2013) 7:e2572. doi: 10.1371/journal.pntd.0002572

180. Abel L, Demenais F, Prata A, Souza AE, Dessein A. Evidence for the segregation of a major gene in human susceptibility/resistance to infection by Schistosoma mansoni. Am J Hum Genet (1991) 48:959-70.

181. Mohamed-Ali Q, Elwali NMA, Abdelhameed AA, Mergani A, Rahoud S, Elagib KE, et al. Susceptibility to Periportal (Symmers) Fibrosis in Human Schistosoma mansoni Infections: Evidence That Intensity and Duration of Infection, Gender, and Inherited Factors Are Critical in Disease Progression. J Infect Dis (1999) 180:1298-306. doi: 10.1086/314999

182. Mitta G, Adema CM, Gourbal B, Loker ES, Theron A. Compatibility polymorphism in snail/schistosome interactions: From field to theory to molecular mechanisms. Dev Comp Immunol (2012) 37:1-8. doi: 10.1016/ j.dci.2011.09.002

183. Mitta G, Gourbal B, Grunau C, Knight M, Bridger JM, Théron A. The Compatibility Between Biomphalaria glabrata Snails and Schistosoma mansoni: An Increasingly Complex Puzzle. Adv Parasitol (2017) 97:111-45. doi: 10.1016/bs.apar.2016.08.006

184. Stothard JR, Sousa-Figueiredo JC, Betson M, Bustinduy A, Reinhard-Rupp J. Schistosomiasis in African infants and preschool children: let them now be treated! Trends Parasitol (2013) 29:197-205. doi: 10.1016/j.pt.2013.02.001

185. Jørgensen A, Kristensen TK, Stothard JR. An investigation of the "Ancyloplanorbidae" (Gastropoda, Pulmonata, Hygrophila): Preliminary evidence from DNA sequence data. Mol Phylogenet Evol (2004) 32:778-87. doi: 10.1016/j.ympev.2004.02.011

186. Jørgensen A, Kristensen TK, Stothard JR. Phylogeny and biogeography of African Biomphalaria (Gastropoda: Planorbidae), with emphasis on endemic species of the great East African lakes. Zool J Linn Soc (2007) 151:337-49. doi: 10.1111/j.1096-3642.2007.00330.x

187. Kazibwe F, Makanga B, Rubaire-Akiiki C, Ouma J, Kariuki C, Kabatereine NB, et al. Ecology of Biomphalaria (Gastropoda: Planorbidae) in Lake Albert, Western Uganda: snail distributions, infection with schistosomes and 
temporal associations with environmental dynamics. Hydrobiologia (2006) 568:433-44. doi: 10.1007/s10750-006-0224-y

188. Mandahl Barth G. The freshwater mollusks of Uganda and adjacent territories. Annales du Musée Royal du Congo Belge, Sciences Zoologiques (1954) 32:1-206.

189. Brown DS. Freshwater Snails Of Africa And Their Medical Importance. 2nd Ed. London, UK: Taylor and Francis (1994). doi: 10.1201/9781482295184

190. Dumont M, Moné H, Mouahid G, Idris MA, Shaban M, Boissier J. Influence of pattern of exposure, parasite genetic diversity and sex on the degree of protection against reinfection with Schistosoma mansoni. Parasitol Res (2007) 101:247. doi: 10.1007/s00436-007-0476-0

191. Beltran S, Gourbal B, Boissier J, Duval D, Kieffer-Jaquinod S, Pierce RJ, et al. Vertebrate host protective immunity drives genetic diversity and antigenic polymorphism in Schistosoma mansoni. J Evol Biol (2011) 24:554-72. doi: $10.1111 / j .1420-9101.2010 .02190 . x$

192. Fu CL, Odegaard JI, Herbert DR, Hsieh MH. A novel mouse model of schistosoma haematobium egg-induced immunopathology. PloS Pathog (2012) 8:e1002605. doi: 10.1371/journal.ppat.1002605

193. Richardson ML, Fu CL, Pennington LF, Honeycutt JD, Odegaard JL, Hsieh YJ, et al. A New Mouse Model for Female Genital Schistosomiasis. PloS Negl Trop Dis (2014) 8:2-9. doi: 10.1371/journal.pntd.0002825

194. Kamel IA, Elwi AM, Cheever AW, Mosimann JE, Danner R. Schistosoma mansoni and S. haematobium infections in Egypt. IV. Hepatic lesions. Am J Trop Med Hyg (1978) 27:931-8. doi: 10.4269/ajtmh.1978.27.931

195. Homeida M, Ahmed S, Dafalla A, Suliman S, Eltom I, Nash T, et al. Morbidity associated with Schistosoma mansoni infection as determined by ultrasound: a study in Gezira, Sudan. Am J Trop Med Hyg (1988) 39:196-201. doi: 10.4269/ajtmh.1988.39.196

196. Berhe N, Myrvang B, Gundersen SG. Intensity of Schistosoma mansoni, hepatitis $\mathrm{B}$, age, and sex predict levels of hepatic periportal thickening/ fibrosis (PPT/F): A large-scale community-based study in Ethiopia. Am J Trop Med Hyg (2007) 77:1079-86. doi: 10.4269/ajtmh.2007.77.1079

197. Homeida MA, Tom I, Nash T, Bennett JL. Association of the therapeutic activity of praziquantel with the reversal of Symmers' fibrosis induced by Schistosoma mansoni. Am J Trop Med Hyg (1991) 45:360-5. doi: 10.4269/ ajtmh.1991.45.360

198. Homeida MM, Eltoum IA, Ali MM, Suliaman SM, Elobied EA, Mansour M, et al. The effectiveness of annual versus biennial mass chemotherapy in reducing morbidity due to schistosomiasis: a prospective study in Gezira-Managil, Sudan. Am J Trop Med Hyg (1996) 54:140-5. doi: 10.4269/ajtmh.1996.54.140

199. Berhe N, Myrvang B, Gundersen SG. Reversibility of schistosomal periportal thickening/fibrosis after praziquantel therapy: a twenty-six month follow-up study in Ethiopia. Am J Trop Med Hyg (2008) 78:228-34. doi: 10.4269/ ajtmh.2008.78.228

200. Mohamed-Ali Q, Doehring-Schwerdtfeger E, Abdel-Rahim IM, Schlake J, Kardorff R, Franke D, et al. Ultrasonographical investigation of periportal fibrosis in children with Schistosoma mansoni infection: reversibility of morbidity seven months after treatment with praziquantel. Am J Trop Med Hyg (1991) 44:444-51. doi: 10.4269/ajtmh.1991.44.444

201. Doehring-Schwerdtfeger E, Abdel-Rahim IM, Kardorff R, Kaiser C, Franke D, Schlake J, et al. Ultrasonographical Investigation of Periportal Fibrosis in Children with Schistosoma mansoni Infection: Reversibility of Morbidity Twenty-Three Months after Treatment with Praziquantel. Am J Trop Med Hyg (1992) 46:409-15. doi: 10.4269/ajtmh.1992.46.409

202. Von Lichtenberg F, Edington GM, Nwabuebo I, Taylor JR, Smith JH. Pathologic effects of schistomiasis in Ibadan Western State of Nigeria. II. Pathogenesis of lesions of the bladder and ureters. Am J Trop Med Hyg (1971) 20:244-54. doi: 10.4269/ajtmh.1971.20.244

203. Christie JD, Crouse D, Pineda J, Anis-Ishak E, Smith JH, Kamel IA. Patterns of Schistosoma haematobium egg distribution in the human lower urinary tract. I. Noncancerous lower urinary tracts. Am J Trop Med Hyg (1986) 35:743-51. doi: 10.4269/ajtmh.1986.35.743

204. Smith JH, Torky H, Kelada AS, Farid Z. Schistosomal polyposis of the urinary bladder. Am J Trop Med Hyg (1977) 26:85-8. doi: 10.4269/ajtmh.1977.26.85

205. Wagatsuma Y, Aryeetey ME, Sack DA, Morrow RH, Hatz C, Kojima S. Resolution and Resurgence of Schistosoma haematobium-induced Pathology After Community-based Chemotherapy in Ghana, as Detected by Ultrasound. J Infect Dis (1999) 179:1515-22. doi: 10.1086/314786
206. Doehring E, Ehrich JH, Reider F, Dittrich M, Schmidt-Ehry G, Brodehl J. Morbidity in urinary schistosomiasis: relation between sonographical lesions and pathological urine findings. Trop Med Parasitol (1985) 36:145-9.

207. King CH, Keating CE, Muruka JF, Ouma JH, Houser H, Siongok TK, et al. Urinary tract morbidity in schistosomiasis haematobia: associations with age and intensity of infection in an endemic area of Coast Province, Kenya. Am J Trop Med Hyg (1988) 39:361-8. doi: 10.4269/ajtmh.1988.39.361

208. Traore M, Traore HA, Kardorff R, Diarra A, Landoure A, Vester U, et al. The public health significance of urinary schistosomiasis as a cause of morbidity in two districts in Mali. Am J Trop Med Hyg (1998) 59:407-13. doi: 10.4269/ ajtmh.1998.59.407

209. Hatz CF, Vennervald BJ, Nkulila T, Vounatsou P, Kombe Y, Mayombana C, et al. Evolution of Schistosoma haematobium-related pathology over 24 months after treatment with praziquantel among school children in southeastern Tanzania. Am J Trop Med Hyg (1998) 59:775-81. doi: 10.4269/ajtmh.1998.59.775

210. Reimert CM, Mshinda HM, Hatz CF, Kombe Y, Nkulila T, Poulsen LK, et al. Quantitative assessment of eosinophiluria in Schistosoma haematobium infections: a new marker of infection and bladder morbidity. Am J Trop Med Hyg (2000) 62:19-28. doi: 10.4269/ajtmh.2000.62.19

211. McManus DP, Dunne DW, Sacko M, Utzinger J, Vennervald BJ, Zhou XN. Schistosomiasis. Nat Rev Dis Primers (2018) 4:1-19. doi: 10.1038/s41572018-0013-8

212. Pearce EJ, MacDonald AS. The immunobiology of schistosomiasis. Nat Rev Immunol (2002) 2:499-511. doi: 10.1038/nri843

213. Schwartz C, Fallon PG. Schistosoma "Eggs-Iting" the Host: Granuloma Formation and Egg Excretion. Front Immunol (2018) 9:2492. doi: 10.3389/ fimmu.2018.02492

214. Hams E, Aviello G, Fallon PG. The schistosoma granuloma: friend or foe? Front Immunol (2013) 4:89. doi: 10.3389/fimmu.2013.00089

215. Wynn TA, Thompson RW, Cheever AW, Mentink-Kane MM. Immunopathogenesis of schistosomiasis. Immunol Rev (2004) 201:156-67. doi: 10.1111/j.0105-2896.2004.00176.x

216. Dunne DW, Jones FM, Doenhoff MJ. The purification, characterization, serological activity and hepatotoxic properties of two cationic glycoproteins (alpha 1 and omega 1) from Schistosoma mansoni eggs. Parasitology (1991) 103(Pt 2):225-36. doi: 10.1017/s0031182000059503

217. Everts B, Perona-Wright G, Smits $\mathrm{HH}$, Hokke $\mathrm{CH}$, van der Ham AJ, Fitzsimmons CM, et al. Omega-1, a glycoprotein secreted by Schistosoma mansoni eggs, drives Th2 responses. J Exp Med (2009) 206:1673-80. doi: 10.1084/jem.20082460

218. Steinfelder S, Andersen JF, Cannons JL, Feng CG, Joshi M, Dwyer D, et al. The major component in schistosome eggs responsible for conditioning dendritic cells for Th2 polarization is a T2 ribonuclease (omega-1). J Exp Med (2009) 206:1681-90. doi: 10.1084/jem.20082462

219. Kouriba B, Chevillard C, Bream JH, Argiro L, Dessein H, Arnaud V, et al. Analysis of the 5q31-q33 locus shows an association between IL13-1055C/T IL-13-591A/G polymorphisms and Schistosoma haematobium infections. J Immunol (2005) 174:6274-81. doi: 10.4049/jimmunol.174.10.6274

220. Marquet S, Abel L, Hillaire D, Dessein H, Kalil J, Feingold J, et al. Genetic localization of a locus controlling the intensity of infection by Schistosoma mansoni on chromosome 5q31-q33. Nat Genet (1996) 14:181-4. doi: $10.1038 /$ ng $1096-181$

221. Oettle RC, Wilson S. The Interdependence between Schistosome Transmission and Protective Immunity. Trop Med Infect Dis (2017) 2:221. doi: 10.3390/tropicalmed 2030042

222. Silveira-Lemos D, Teixeira-Carvalho A, Martins-Filho OA, Alves Oliveira LF, Costa-Silva MF, Matoso LF, et al. Eosinophil activation status, cytokines and liver fibrosis in Schistosoma mansoni infected patients. Acta Trop (2008) 108:150-9. doi: 10.1016/j.actatropica.2008.04.006

223. Shao DD, Suresh R, Vakil V, Gomer RH, Pilling D. Pivotal Advance: Th-1 cytokines inhibit, and Th-2 cytokines promote fibrocyte differentiation. J Leukoc Biol (2008) 83:1323-33. doi: 10.1189/jlb.1107782

224. Joseph S, Jones FM, Kimani G, Mwatha JK, Kamau T, Kazibwe F, et al. Cytokine production in whole blood cultures from a fishing community in an area of high endemicity for Schistosoma mansoni in Uganda: the differential effect of parasite worm and egg antigens. Infect Immun (2004) 72:728-34. doi: 10.1128/iai.72.2.728-734.2004 
225. Wilson S, Jones FM, Mwatha JK, Kimani G, Booth M, Kariuki HC, et al. Hepatosplenomegaly Is Associated with Low Regulatory and Th2 Responses to Schistosome Antigens in Childhood Schistosomiasis and Malaria Coinfection. Infect Immun (2008) 76:2212 -18. doi: 10.1128/IAI.01433-07

226. Colley DG, Garcia AA, Lambertucci JR, Parra JC, Katz N, Rocha RS, et al. Immune responses during human schistosomiasis. XII. Differential responsiveness in patients with hepatosplenic disease. Am J Trop Med Hyg (1986) 35:793-802. doi: 10.4269/ajtmh.1986.35.793

227. de Jesus AR, Magalhães A, Miranda DG, Miranda RG, Araújo MI, de Jesus AA, et al. Association of type 2 cytokines with hepatic fibrosis in human Schistosoma mansoni infection. Infect Immun (2004) 72:3391-7. doi: 10.1128/IAI.72.6.3391-3397.2004

228. Alves Oliveira LF, Moreno EC, Gazzinelli G, Martins-Filho OA, Silveira AMS, Gazzinelli A, et al. Cytokine Production Associated with Periportal Fibrosis during Chronic Schistosomiasis Mansoni in Humans. Infect Immun (2006) 74:1215-21. doi: 10.1128/IAI.74.2.1215-1221.2006

229. Magalhães A, Miranda DG, Miranda RG, Araújo MI, de Jesus AA, Silva A, et al. Cytokine profile associated with human chronic schistosomiasis mansoni. Mem Inst Oswaldo Cruz (2004) 99:21-6. doi: 10.1590/s007402762004000900004

230. Fallon PG, Richardson EJ, McKenzie GJ, McKenzie AN. Schistosome infection of transgenic mice defines distinct and contrasting pathogenic roles for IL-4 and IL-13: IL-13 is a profibrotic agent. J Immunol (2000) 164:2585-91. doi: 10.4049/jimmunol.164.5.2585

231. Cheever AW, Williams ME, Wynn TA, Finkelman FD, Seder RA, Cox TM, et al. Anti-IL-4 treatment of Schistosoma mansoni-infected mice inhibits development of $\mathrm{T}$ cells and non-B, non-T cells expressing Th2 cytokines while decreasing egg-induced hepatic fibrosis. J Immunol (1994) 153:753-9.

232. Reiman RM, Thompson RW, Feng CG, Hari D, Knight R, Cheever AW, et al. Interleukin-5 (IL-5) augments the progression of liver fibrosis by regulating IL-13 activity. Infect Immun (2006) 74:1471-9. doi: 10.1128/IAI.74.3.14711479.2006

233. Lee CG, Homer RJ, Zhu Z, Lanone S, Wang X, Koteliansky V, et al. Interleukin-13 induces tissue fibrosis by selectively stimulating and activating transforming growth factor beta(1). J Exp Med (2001) 194:809-21. doi: 10.1084/jem.194.6.809

234. Cook PC, Owen H, Deaton AM, Borger JG, Brown SL, Clouaire T, et al. A dominant role for the methyl-CpG-binding protein Mbd2 in controlling Th2 induction by dendritic cells. Nat Commun (2015) 6:1-11. doi: 10.1038/ ncomms 7920

235. Deaton AM, Cook PC, De Sousa D, Phythian-Adams AT, Bird A, Macdonald AS. A unique DNA methylation signature defines a population of IFN- $\gamma / \mathrm{IL}-4$ double-positive $\mathrm{T}$ cells during helminth infection. Eur J Immunol (2014) 44:1835-41. doi: 10.1002/eji.201344098

236. Ishii M, Wen H, Corsa CAS, Liu T, Coelho AL, Allen RM, et al. Epigenetic regulation of the alternatively activated macrophage phenotype. Blood (2009) 114:3244-54. doi: 10.1182/blood-2009-04-217620

237. Norseth HM, Ndhlovu PD, Kleppa E, Randrianasolo BS, Jourdan PM, Roald B, et al. The Colposcopic Atlas of Schistosomiasis in the Lower Female Genital Tract Based on Studies in Malawi, Zimbabwe, Madagascar and South Africa. PloS Negl Trop Dis (2014) 8:e3229. doi: 10.1371/journal.pntd.0003229

238. Dukes DC, Macdougall BR, Orne-Gliemann RH, Davidson L. Urinary leucocyte excretion in African subjects: its relation to bacteriuria and the passage of bilharzial ova in urine. $\mathrm{Br}$ Med J (1967) 1:537. doi: 10.1136/ bmj.1.5539.537

239. Doehring E, Ehrich JHH, Vester U, Feldmeier H, Poggensee U, Brodehl J. Proteinuria, hematuria, and leukocyturia in children with mixed urinary and intestinal schistosomiasis. Kidney Int (1985) 28:520-5. doi: 10.1038/ ki.1985.159

240. Eltoum IA, Suliaman SM, Ismail BM, Ismail AI, Ali MM, Homeida MM. Evaluation of eosinophiluria in the diagnosis of schistosomiasis hematobium: a field-based study. Am J Trop Med Hyg (1992) 46:732-6. doi: 10.4269/ajtmh.1992.46.732

241. Ramarokoto CE, Kildemoes AO, Randrianasolo BS, Ravoniarimbinina P, Ravaoalimalala VE, Leutscher P, et al. Eosinophil granule proteins ECP and EPX as markers for a potential early-stage inflammatory lesion in female genital schistosomiasis (FGS). PloS Negl Trop Dis (2014) 8:e2974. doi: 10.1371/journal.pntd.0002974
242. Midzi N, Ndhlovu PD, Nyanga L, Kjetland EF, Reimert CM, Vennervald BJ, et al. Assessment of eosinophil cationic protein as a possible diagnostic marker for female genital schistosomiasis in women living in a Schistosoma haematobium endemic area. Parasite Immunol (2003) 25:581-8. doi: 10.1111/j.0141-9838.2004.00670.x

243. Reimert CM, Ouma JH, Mwanje MT, Magak P, Poulsen LK, Vennervald BJ, et al. Indirect assessment of eosinophiluria in urinary schistosomiasis using eosinophil cationic protein (ECP) and eosinophil protein X (EPX). Acta Trop (1993) 54:1-12. doi: 10.1016/0001-706x(93)90063-h

244. Kita H. Eosinophils: multifaceted biological properties and roles in health and disease. Immunol Rev (2011) 242:161-77. doi: 10.1111/j.1600065X.2011.01026.X

245. Eriksson J, Reimert CM, Kabatereine NB, Kazibwe F, Ireri E, Kadzo H, et al. The $434(\mathrm{G}>\mathrm{C})$ polymorphism within the coding sequence of Eosinophil Cationic Protein (ECP) correlates with the natural course of Schistosoma mansoni infection. Int J Parasitol (2007) 37:1359-66. doi: 10.1016/ j.ijpara.2007.04.001

246. Zwingenberger K, Irschick E, Siqueira JGV, Dacal ARC, Feldmeier H. Tumour Necrosis Factor in Hepatosplenic Schistosomiasis. Scand J Immunol (1990) 31:205-11. doi: 10.1111/j.1365-3083.1990.tb02761.x

247. Booth M, Mwatha JK, Joseph S, Jones FM, Kadzo H, Ireri E, et al. Periportal fibrosis in human Schistosoma mansoni infection is associated with low IL10, low IFN-gamma, high TNF-alpha, or low RANTES, depending on age and gender. J Immunol (2004) 172:1295-303. doi: 10.4049/ jimmunol.172.2.1295

248. Mwatha JK, Kimani G, Kamau T, Mbugua GG, Ouma JH, Mumo J, et al. High levels of TNF, soluble TNF receptors, soluble ICAM-1, and IFNgamma, but low levels of IL-5, are associated with hepatosplenic disease in human schistosomiasis mansoni. J Immunol (1998) 160:1992-9.

249. Henri S, Chevillard C, Mergani A, Paris P, Gaudart J, Camilla C, et al. Cytokine regulation of periportal fibrosis in humans infected with Schistosoma mansoni: IFN-gamma is associated with protection against fibrosis and TNF-alpha with aggravation of disease. J Immunol (2002) 169:929-36. doi: 10.4049/jimmunol.169.2.929

250. Vennervald BJ, Kenty L, Butterworth AE, Kariuki CH, Kadzo H, Ireri E, et al. Detailed clinical and ultrasound examination of children and adolescents in a Schistosoma mansoni endemic area in Kenya: hepatosplenic disease in the absence of portal fibrosis. Trop Med Int Health (2004) 9:461-70. doi: 10.1111/j.1365-3156.2004.01215.x

251. Wilson S, Jones FM, Kenty L-C, Mwatha JK, Kimani G, Kariuki HC, et al. Posttreatment changes in cytokines induced by Schistosoma mansoni egg and worm antigens: dissociation of immunity- and morbidity-associated type 2 responses. J Infect Dis (2014) 209:1792-800. doi: 10.1093/infdis/jit826

252. Cheever AW, Lenzi JA, Lenzi HL, Andrade ZA. Experimental models of Schistosoma mansoni infection. Mem Inst Oswaldo Cruz (2002) 97:917-40. doi: 10.1590/s0074-02762002000700002

253. Eboumbou Moukoko C, El Wali N, Saeed OK, Mohamed-Ali Q, Gaudart J, Dessein AJ, et al. No Evidence for a Major Effect of Tumor Necrosis Factor Alpha Gene Polymorphisms in Periportal Fibrosis Caused by \&lt; $\mathrm{em}<$ Schistosoma mansoni\&lt;/em $<$ Infection. Infect Immun (2003) 71:5456- 60. doi: 10.1128/IAI.71.10.5456-5460.2003

254. Silva PCV, Gomes AV, de Britto LRPB, de Lima ELS, da Silva JL, Montenegro SML, et al. Influence of a TNF- $\alpha$ Polymorphism on the Severity of Schistosomiasis Periportal Fibrosis in the Northeast of Brazil. Genet Test Mol Biomarkers (2017) 21:658-62. doi: 10.1089/gtmb.2017.0133

255. King CL, Malhotra I, Mungai P, Wamachi A, Kioko J, Muchiri E, et al. Schistosoma haematobium-induced urinary tract morbidity correlates with increased tumor necrosis factor-alpha and diminished interleukin-10 production. J Infect Dis (2001) 184:1176-82. doi: 10.1086/323802

256. Wamachi AN, Mayadev JS, Mungai PL, Magak PL, Ouma JH, Magambo JK, et al. Increased Ratio of Tumor Necrosis Factor- $\alpha$ to Interleukin-10 Production Is Associated with Schistosoma haematobium-Induced Urinary-Tract Morbidity. J Infect Dis (2004) 190:2020-30. doi: 10.1086/ 425579

257. Baroni GS, D’Ambrosio L, Curto P, Casini A, Mancini R, Jezequel AM, et al. Interferon gamma decreases hepatic stellate cell activation and extracellular matrix deposition in rat liver fibrosis. Hepatology (1996) 23:1189-99. doi: 10.1002/hep.510230538 
258. Ulloa L, Doody J, Massagué J. Inhibition of transforming growth factor-beta/ SMAD signalling by the interferon-gamma/STAT pathway. Nature (1999) 397:710-3. doi: 10.1038/17826

259. Boros DL, Lukacs NW. The role of egg antigens, cytokines in granuloma formation in murine schistosomiasis mansoni. Mem Inst Oswaldo Cruz (1992) 87(Suppl 4):75-9. doi: 10.1590/s0074-02761992000800010

260. Hoffmann KF, Cheever AW, Wynn TA. IL-10 and the dangers of immune polarization: excessive type 1 and type 2 cytokine responses induce distinct forms of lethal immunopathology in murine schistosomiasis. J Immunol (2000) 164:6406-16. doi: 10.4049/jimmunol.164.12.6406

261. DiNardo AR, Nishiguchi T, Mace EM, Rajapakshe K, Mtetwa G, Kay A, et al. Schistosomiasis Induces Persistent DNA Methylation and TuberculosisSpecific Immune Changes. J Immunol (2018) 201:124-33. doi: 10.4049/ jimmunol.1800101

262. Farah IO, Nyindo M, Suleman MA, Nyaundi J, Kariuki TM, Blanton RE, et al. Schistosoma mansoni: development and modulation of the granuloma after or multiple exposures in the baboon (Papio cynocephalus anubis). Exp Parasitol (1997) 86:93-101. doi: 10.1006/expr.1997.4152

263. Weinstock JV, Boros DL. Heterogeneity of the granulomatous response in the liver, colon, ileum, and ileal Peyer's patches to schistosome eggs in murine schistosomiasis mansoni. J Immunol (1981) 127:1906-9.

264. Colley DG. Adoptive suppression of granuloma formation. J Exp Med (1976) 143:696-700. doi: 10.1084/jem.143.3.696

265. Chensue SW, Boros DL, David CS. Regulation of granulomatous inflammation in murine schistosomiasis. In vitro characterization of $\mathrm{T}$ lymphocyte subsets involved in the production and suppression of migration inhibition factor. J Exp Med (1980) 151:1398-412. doi: 10.1084/ jem.151.6.1398

266. Ferru I, Roye O, Delacre M, Auriault C, Wolowczuk I. Infection of B-celldeficient mice by the parasite Schistosoma mansoni: demonstration of the participation of B cells in granuloma modulation. Scand J Immunol (1998) 48:233-40. doi: 10.1046/j.1365-3083.1998.00376.x

267. Jankovic D, Cheever AW, Kullberg MC, Wynn TA, Yap G, Caspar P, et al. CD4+ $\mathrm{T}$ cell-mediated granulomatous pathology in schistosomiasis is downregulated by a B cell-dependent mechanism requiring $\mathrm{Fc}$ receptor signaling. J Exp Med (1998) 187:619-29. doi: 10.1084/jem.187.4.619

268. Yap G, Cheever A, Caspar P, Jankovic D, Sher A. Unimpaired downmodulation of the hepatic granulomatous response in CD8 T-cell- and gamma interferon-deficient mice chronically infected with Schistosoma mansoni. Infect Immun (1997) 65:2583-6. doi: 10.1128/IAI.65.7.25832586.1997

269. Watanabe K, Mwinzi PNM, Black CL, Muok EMO, Karanja DMS, Secor WE, et al. T regulatory cell levels decrease in people infected with Schistosoma mansoni on effective treatment. Am J Trop Med Hyg (2007) 77:676-82. doi: 10.4269/ajtmh.2007.77.676

270. Schmiedel Y, Mombo-Ngoma G, Labuda LA, Janse JJ, de Gier B, Adegnika AA, et al. CD4+CD25hiFOXP3+ Regulatory T Cells and Cytokine Responses in Human Schistosomiasis before and after Treatment with Praziquantel. PloS Negl Trop Dis (2015) 9:e0003995. doi: 10.1371/journal.pntd.0003995

271. Ondigo BN, Ndombi EM, Nicholson SC, Oguso JK, Carter JM, Kittur N, et al. Functional Studies of $\mathrm{T}$ Regulatory Lymphocytes in Human Schistosomiasis in Western Kenya. Am J Trop Med Hyg (2018) 98:1770-81. doi: 10.4269/ajtmh.17-0966

272. van der Vlugt LEPM, Mlejnek E, Ozir-Fazalalikhan A, Janssen Bonas M, Dijksman TR, Labuda LA, et al. CD24(hi)CD27(+) B cells from patients with allergic asthma have impaired regulatory activity in response to lipopolysaccharide. Clin Exp Allergy (2014) 44:517-28. doi: 10.1111/ cea. 12238

273. Singh KP, Gerard HC, Hudson AP, Reddy TR, Boros DL. Retroviral Foxp3 gene transfer ameliorates liver granuloma pathology in Schistosoma mansoni infected mice. Immunology (2005) 114:410-7. doi: 10.1111/j.13652567.2004.02083.x

274. Taylor JJ, Mohrs M, Pearce EJ. Regulatory T cell responses develop in parallel to Th responses and control the magnitude and phenotype of the Th effector population. J Immunol (2006) 176:5839-47. doi: 10.4049/jimmunol.176.10.5839

275. Hesse M, Piccirillo CA, Belkaid Y, Prufer J, Mentink-Kane M, Leusink M, et al. The pathogenesis of schistosomiasis is controlled by cooperating IL-10- producing innate effector and regulatory T cells. J Immunol (2004) 172:3157-66. doi: 10.4049/jimmunol.172.5.3157

276. McKee AS, Pearce EJ. CD25+CD4+ cells contribute to Th2 polarization during helminth infection by suppressing Th1 response development. J Immunol (2004) 173:1224-31. doi: 10.4049/jimmunol.173.2.1224

277. Wynn TA, Cheever AW, Williams ME, Hieny S, Caspar P, Kühn R, et al. IL10 regulates liver pathology in acute murine Schistosomiasis mansoni but is not required for immune down-modulation of chronic disease. J Immunol (1998) 160:4473-80.

278. Zdesenko G, Mutapi F. Drug metabolism and pharmacokinetics of praziquantel: A review of variable drug exposure during schistosomiasis treatment in human hosts and experimental models. PloS Negl Trop Dis (2020) 14:1-26. doi: 10.1371/journal.pntd.0008649

279. el Guiniady MA, el Touny MA, Abdel-Bary MA, Abdel-Fatah SA, Metwally A. Clinical and pharmacokinetic study of praziquantel in Egyptian schistosomiasis patients with and without liver cell failure. Am J Trop Med Hyg (1994) 51:809-18. doi: 10.4269/ajtmh.1994.51.809

280. Klar K, Perchermeier S, Bhattacharjee S, Harb H, Adler T, Istvanffy R, et al. Chronic schistosomiasis during pregnancy epigenetically reprograms $\mathrm{T}$-cell differentiation in offspring of infected mothers. Eur J Immunol (2017) 47:841-7. doi: 10.1002/eji.201646836

281. Maizels RM, Smits HH, McSorley HJ. Modulation of Host Immunity by Helminths: The Expanding Repertoire of Parasite Effector Molecules. Immunity (2018) 49:801-18. doi: 10.1016/j.immuni.2018.10.016

282. Haeberlein S, Obieglo K, Ozir-Fazalalikhan A, Chayé MAM, Veninga H, van der Vlugt LEPM, et al. Schistosome egg antigens, including the glycoprotein IPSE/alpha-1, trigger the development of regulatory B cells. PloS Pathog (2017) 13:e1006539. doi: 10.1371/journal.ppat.1006539

283. Nelson GS. Schistosoma mansoni Infection in the West Nile District of Uganda. Part III. The Spleen and S. mansoni Infection. East Afr Med J (1958) 35:543-7.

284. Parker M, Allen T, Hastings J. Resisting control of neglected tropical diseases: dilemmas in the mass treatment of schistosomiasis and soiltransmitted helminths in north-west Uganda. J Biosoc Sci (2008) 40:161-81. doi: 10.1017/S0021932007002301

285. Opio CK, Kazibwe F, Ocama P, Rejani L, Belousova EN, Ajal P. Profiling lifetime episodes of upper gastrointestinal bleeding among patients from rural Sub-Saharan Africa where schistosoma mansoni is endemic. Pan Afr Med J (2016) 24:1-9. doi: 10.11604/pamj.2016.24.296.9755

286. Pinot de Moira A, Fulford AJC, Kabatereine NB, Kazibwe F, Ouma JH, Dunne DW, et al. Microgeographical and tribal variations in water contact and Schistosoma mansoni exposure within a Ugandan fishing community. Trop Med Int Health (2007) 12:724-35. doi: 10.1111/j.1365-3156.2007.01842.x

287. Dessein AJ, Couissinier P, Demeure C, Rihet P, Kohlstaedt S, CarneiroCarvalho D, et al. Environmental, Genetic and Immunological Factors in Human Resistance to Schistosoma Mansoni. Immunol Invest (1992) 21:423-53. doi: $10.3109 / 08820139209069383$

288. King CH, Olbrych SK, Soon M, Singer ME, Carter J, Colley DG. Utility of repeated praziquantel dosing in the treatment of schistosomiasis in high-risk communities in Africa: A systematic review. PloS Negl Trop Dis (2011) 5: e1321. doi: 10.1371/journal.pntd.0001321

289. Afifi MA, Jiman-fatani AA, Al-hussainy NH, Al-rabia MW, Bogari AA. Genetic diversity among natural populations of Schistosoma haematobium might contribute to inconsistent virulence and diverse clinical outcomes. J Microsc Ultrastruct (2016) 4:222-7. doi: 10.1016/j.jmau.2016.04.002

Conflict of Interest: The authors declare that the research was conducted in the absence of any commercial or financial relationships that could be construed as a potential conflict of interest.

Copyright (c) 2021 Mawa, Kincaid-Smith, Tukahebwa, Webster and Wilson. This is an open-access article distributed under the terms of the Creative Commons Attribution License (CC BY). The use, distribution or reproduction in other forums is permitted, provided the original author(s) and the copyright owner(s) are credited and that the original publication in this journal is cited, in accordance with accepted academic practice. No use, distribution or reproduction is permitted which does not comply with these terms. 